\title{
Protein-Protein Interaction Changes in an Archaeal Light-Signal Transduction
}

\author{
Hideki Kandori, ${ }^{1}$ Yuki Sudo, ${ }^{2}$ and Yuji Furutani ${ }^{3}$ \\ ${ }^{1}$ Department of Frontier Materials, Nagoya Institute of Technology, Showa-ku, Nagoya 466-8555, Japan \\ ${ }^{2}$ Division of Biological Science, Graduate School of Science, Nagoya University, Chikusa-ku, Nagoya 464-8602, Japan \\ ${ }^{3}$ Department of Life and Coordination-Complex Molecular Science, Institute for Molecular Science, Myodaiji, \\ Okazaki 444-8585, Japan \\ Correspondence should be addressed to Hideki Kandori, kandori@nitech.ac.jp
}

Received 28 December 2009; Accepted 5 May 2010

Academic Editor: Juan Fernández-Recio

Copyright ( $) 2010$ Hideki Kandori et al. This is an open access article distributed under the Creative Commons Attribution License, which permits unrestricted use, distribution, and reproduction in any medium, provided the original work is properly cited.

\begin{abstract}
Negative phototaxis in Natronomonas pharaonis is initiated by transient interaction changes between photoreceptor and transducer. pharaonis phoborhodopsin ( $p \mathrm{pR}$; also called pharaonis sensory rhodopsin II, psR-II) and the cognate transducer protein, $p$ HtrII, form a tight $2: 2$ complex in the unphotolyzed state, and the interaction is somehow altered during the photocycle of $p \mathrm{pR}$. We have studied the signal transduction mechanism in the $p \mathrm{pR} / p$ HtrII system by means of low-temperature Fouriertransform infrared (FTIR) spectroscopy. In the paper, spectral comparison in the absence and presence of $p$ HtrII provided fruitful information in atomic details, where vibrational bands were identified by the use of isotope-labeling and site-directed mutagenesis. From these studies, we established the two pathways of light-signal conversion from the receptor to the transducer; (i) from Lys205 (retinal) of $p$ pR to Asn74 of $p$ HtrII through Thr204 and Tyr199, and (ii) from Lys205 of $p$ pR to the cytoplasmic loop region of $p$ HtrII that links Gly83.
\end{abstract}

\section{Introduction}

Biological signal transduction is based on protein-protein interaction and its transient changes. In some cases, two proteins are without interactions but form a transient protein-protein complex upon signal input. In another case, two proteins form a complex, while the interaction is changed, either stronger or weaker, upon signal input. These transient changes are normally weak and unstable, and it is not easy to capture these processes experimentally. Then, what is a good transient protein-protein complex to be investigated?

Light-signal transduction, such as our vision and bacterial phototaxis, is highly advantageous to study transient protein-protein interaction changes, because signal input is a light absorbent of photoreceptor. Light illumination is superb stimulius, which is temporally as short as femtoseconds $\left(10^{-15}\right.$ seconds), and never perturbs the system. We have thus studied protein-protein interaction changes in visual and archaeal rhodopsins with their transducer proteins. Both visual $[1-3]$ and archaeal $[4,5]$ rhodopsins possess 7-transmembrane helical architecture, and a retinal molecule is bound to a protein through a protonated Schiff base linkage serving as a chromophore. Photoisomerization of the retinal drives protein structural changes utilized for light-signal transduction. In visual rhodopsin, the transducer is a hetero-trimeric $\mathrm{G}$ protein, both of which do not interact with each other, but form a transient protein-protein complex upon light activation. Light-induced protein-protein association is an important step in our vision, and it is believed that the mechanism of the transducer activation for the rhodopsin/G-protein system is common among other G-protein coupled receptors and G-proteins $[6,7]$. In contrast, archaeal rhodopsins form stable complex with their transducer protein in membrane in the dark, and the protein-protein complex is transiently changed upon light activation. Then, which method is suitable for studying transient protein-protein interaction changes in rhodopsins?

We used Fourier-transform infrared (FTIR) spectroscopy for such study. Unlike X-ray crystallography and NMR, 
vibrational spectroscopy cannot determine the atomic positions of proteins. In the infrared frequency region, there are huge absorptions of not only proteins but also solvent water molecules, which makes it further difficult to analyze the vibrational signals. In contrast, stimulus-induced difference FTIR spectroscopy can extract vibrational signals due to structural changes upon stimuli. In particular, light is an ideal stimulius in terms of high temporal resolution and no perturbation of the system. Light-induced difference FTIR spectroscopy has been extensively applied to the rhodopsin study [8-11], which monitors intramolecular events in rhodopsins. We have also extended this technique to the protein-protein complex between rhodopsin and transducer, where we reported the first paper of visual rhodopsin in 1997 [12], and archaeal rhodopsin in 2003 [13].

It should be particularly noted that FTIR spectroscopy is a powerful method to monitor hydrogen-bonding interactions, which play crucial roles in protein-protein complexes. We have shown the fact by monitoring $\mathrm{O}-\mathrm{H}$ and $\mathrm{N}-\mathrm{H}$ stretching vibrations $\left(\mathrm{O}-\mathrm{D}\right.$ and $\mathrm{N}-\mathrm{D}$ stretches in $\mathrm{D}_{2} \mathrm{O}$ ) in the $4000-2000 \mathrm{~cm}^{-1}$ region of the difference FTIR spectra of rhodopsins [14-18]. Detection of water stretching vibrations is one of the highlights of the study, and we have recently found that strongly hydrogen-bonded water molecules are required for the rhodopsins having protonpumping activity [17]. In this paper, we summarize our FTIR studies on the protein-protein complex in an archaea. pharaonis phoborhodopsin ( $p \mathrm{pR}$; also called pharaonis sensory rhodopsin II, psR-II) is a photoreceptor for negative phototaxis in Natronomonas pharaonis. p pR activates the cognate transducer protein, $p \mathrm{HtrII}$, upon absorption of light. $p \mathrm{pR}$ and $p \mathrm{HtrII}$ form a tight $2: 2$ complex in the unphotolyzed state, and the interaction is somehow altered during the photocycle of $p \mathrm{pR}$. We previously reported structural changes in $p \mathrm{pR}$ itself by means of low-temperature FTIR spectroscopy in 2001 [19]. Unlike visual rhodopsins, $p$ pR forms stable complex with $p \mathrm{HtrII}$ in membrane, so that light-induced spectral changes of the $p \mathrm{pR} / p \mathrm{HtrII}$ complex can be similarly measured as for $p \mathrm{pR}$. Thus, we applied FTIR spectroscopy to the $p \mathrm{pR} / p \mathrm{HtrII}$ complex for the first time in 2003 [13], and since then, we totally published 4 papers [13, 20-22]. This paper aimed at summarizing these studies in the past, informing what was known about the signal-transduction mechanism of the $p \mathrm{pR} / p \mathrm{HtrII}$ complex system. The two papers in 2003 reported the FTIR spectra of the $p \mathrm{pR} / p \mathrm{HtrII}$ complex for the primary $\mathrm{K}$-intermediate $[13,20]$, which is presented in chapter 3 . Then, the following two chapters present the FTIR spectra of the $p \mathrm{pR} / p \mathrm{HtrII}$ complex for the M-intermediate [21, 22], the active state in the signal transduction. In the studies, isotope-labeling and site-directed mutagenesis were used for identifying the vibrational bands in the difference FTIR spectra. Consequently, we were able to reveal the signal-relay pathway from the retinal chromophore to the cytoplasmic region of the transducer protein. Though being entirely unexpected, important role of an amino acid in function was revealed, which is now combined to the structural information.

\section{Protein-Protein Complex between ppR and pHtrII}

$p p R$ is one of the archaeal rhodopsins that have all-trans retinal as a chromophore (Figure 1) [5, 23-26]. The retinal forms a Schiff base linkage with Lys205 in the middle of the seventh transmembrane helix $[27,28]$. ppR serves as a repellent photoreceptor in Natronomonas pharaonis and forms a signaling complex in archaeal membranes with $p H$ trII [29]. $p \mathrm{HtrII}$ is a transmembrane two-helical protein and belongs to a family of transmembrane two-helical methylaccepting chemotaxis proteins (MCPs) [30, 31]. It is well known that MCPs exist as homodimers composed of a 50 $60 \mathrm{kDa}$ subunits and form a ternary complex with CheA and CheW. Chemical stimuli activate phosphorylation cascades that modulate flagella motors [32-34], where MCPs act not only as signal receptors, but also as transducers. In contrast, light signal is received by $p \mathrm{pR}$, a protein different from $p$ HtrII. Therefore, specific interaction is required between $p \mathrm{pR}$ and $p \mathrm{HtrII}[29,35,36] . p \mathrm{pR}$ transmits light signals to $p$ HtrII through the change in such interaction, and $p H$ trII eventually activates phosphorylation cascades that modulate flagella motors (Figure 1). By using the signaling system, the archaea avoid harmful near-UV light, displaying what is called a negative phototaxis. $p \mathrm{pR}$ absorbs maximally at $498 \mathrm{~nm}$, and the light triggers trans-cis photoisomerization of the retinal chromophore in its electronically excited state [37], followed by rapid formation of the ground-state species such as the K-intermediate (Figure 1). Relaxation of the $\mathrm{K}$-intermediate leads to functional processes during the photocycle, where protein structural changes are transmitted from $p$ pR to $p \mathrm{HtrII}$ presumably in the $\mathrm{M}$ and/or $\mathrm{O}$ states [38].

$p \mathrm{pR}$ is stable in membranes and detergent micelles [39], and expression in Escherichia coli cells can provide large amounts of this protein (several $\mathrm{mg} / \mathrm{L}$ culture) [40]. Therefore, $p \mathrm{pR}$ has been well characterized over the past few years using various methods. The crystal structure of $p$ pR was determined in 2001 by two groups [27, 28], which provided surprisingly similar architecture to that of a wellknown proton-pump protein, bacteriorhodopsin. This may be reasonable, because $p \mathrm{pR}$ pumps protons in the absence of $p$ HtrII [41]. It is likely that the transducer binding converts proton pump into light sensor, because the $p \mathrm{pR} / p \mathrm{HtrII}$ complex does not pump protons [41]. Thus, the mechanism of protein-protein interaction between $p \mathrm{pR}$ and $p \mathrm{HtrII}$ and its changes upon light absorption have been attracting interest among researchers.

Successful expression of $p \mathrm{HtrII}$ in Escherichia coli $[42,43]$ and complex formation with $p \mathrm{pR}$ even in detergent also helped studying the protein-protein interaction mechanism. It was found that $p \mathrm{pR}$ and $p \mathrm{HtrII}$ form $2: 2$ complex, whose binding constants were determined under various conditions [42, 44-46]. In 2002, a German group determined the crystal structure of the $p \mathrm{pR} / p \mathrm{HtrII}$ complex [29], which further encouraged understanding of the protein-protein interaction between the 7-transmembrane receptor $(p \mathrm{pR})$ and 2-transmembarne transducer ( $p$ HtrII) (Figure 2). It should be noted that the structure of $p \mathrm{pR}$ is surprisingly 

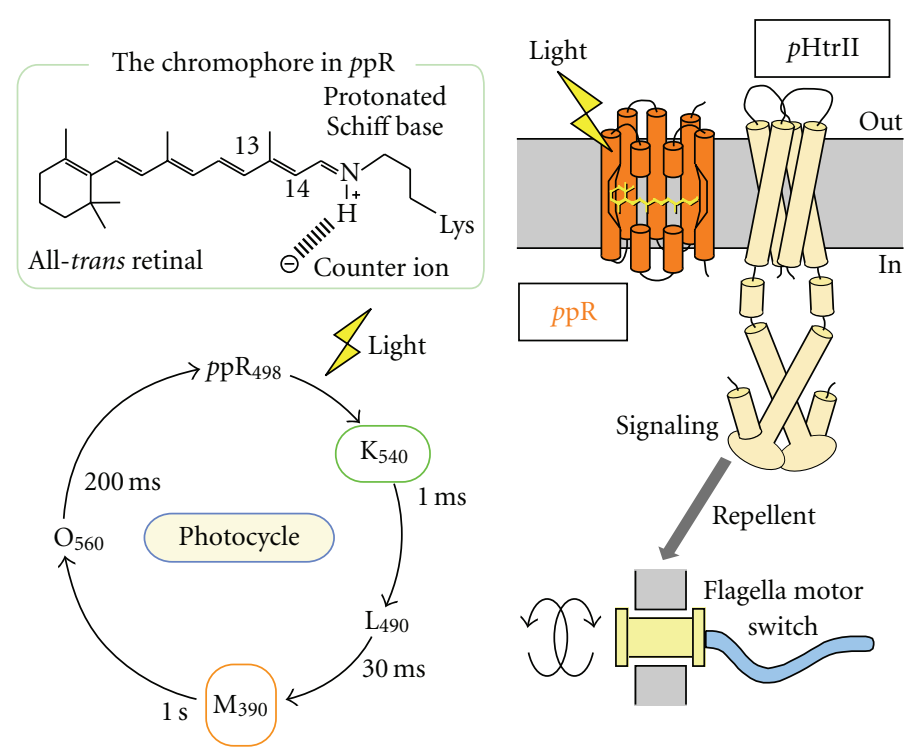

FIGURE 1: Schematic representation of pharaonis phoborhodospin ( $p \mathrm{pR}$ ) and its transducer ( $p \mathrm{HtrII})$. $p \mathrm{pR}$ and $p \mathrm{HtrII}$ form a $2: 2$ complex in the membrane, former of which contains all-trans retinal as the chromophore. $p$ pR absorbs maximally at $498 \mathrm{~nm}$, and light absorption initiates the photocycle. Light signal is transferred into the cytoplasmic domain through the protein structural changes of $p \mathrm{HtrII}$.

similar regardless of the presence or absence of $p$ HtrII. In fact, backbone structures are almost identical, while there are some deviations in side chains [29]. The association between $p \mathrm{pR}$ and $p \mathrm{HtrII}$ originates mostly from van der Waals contacts in the transmembrane region, whereas intermolecular hydrogen bonds are between Tyr199 of $p \mathrm{pR}$ and Asn74 of pHtrII, and between Thr189 of ppR and Glu43/Ser62 of $p$ HtrII (Figure 2). Similar structure of $p \mathrm{pR}$ with or without pHtrII may be also reasonable, because transducer binding does not change the color of $p \mathrm{pR}$ [42]. The pKa of the Schiff base counterion (Asp75) is almost identical for the single $p \mathrm{pR}$ and the $p \mathrm{pR} / p \mathrm{HtrII}$ complex [41], which is in clear contrast to the case in sensory rhodopsin I [47]. The photocycle of $p \mathrm{pR}$ is not much influenced by the presence of pHtrII $[41,48]$, except for the slow-decay kinetics of the M intermediate [42]. Then, a question arises how light signal is transmitted from $p \mathrm{pR}$ to $p \mathrm{HtrII}$. To answer this question, it is important to understand protein structural changes, and our first FTIR paper on the $p \mathrm{pR} / p \mathrm{HtrII}$ complex appeared one year after the structural determination, when we did not know the structure upon writing the manuscript.

\section{Light-Signal Conversion in the K-Intermediate}

Signal transduction in the $p \mathrm{pR} / p \mathrm{HtrII}$ system is initiated by the primary photochemical reaction of the chromophore molecule. Photoisomerization from the all-trans to 13-cis form produces the $\mathrm{K}$ intermediate $\left(p \mathrm{pR}_{\mathrm{K}}\right)$. We first trapped the $\mathrm{K}$ intermediate at $77 \mathrm{~K}$ and then compared the $p \mathrm{pR}_{\mathrm{K}}$ minus $p \mathrm{pR}$ spectra with and without $p$ HtrII [13]. The observed FTIR spectra were very similar, indicating that the complex formation between $p \mathrm{pR}$ and $p \mathrm{HtrII}$ has almost no effect on the structural alterations which happen upon retinal photoisomerization. The result is consistent with the same absorption spectra of $p \mathrm{pR}$ with and without $p$ HtrII. In particular, there are no spectral changes for the X-D stretching vibrations $\left(2700-1900 \mathrm{~cm}^{-1}\right)$ caused by presence of $p \mathrm{HtrII}$, indicating that the hydrogen-bonding network in the Schiff base region is not altered by the interaction with $p \mathrm{HtrII}[13]$.

On the other hand, a spectral difference was observed in the frequency region of amide-I vibration that monitors structural alterations of peptide backbone. Figure 3 shows the $p \mathrm{pR}_{\mathrm{K}}$ minus $p \mathrm{pR}$ spectra in the $1720-1615 \mathrm{~cm}^{-1}$ region. There are two negative peaks at 1657 and $1651 \mathrm{~cm}^{-1}$ in the absence of $p \mathrm{HtrII}$ (dotted line in Figure 3(a)). These frequencies are characteristic of amide-I vibration of $\alpha$-helix. The $\mathrm{C}=\mathrm{N}$ stretching vibration of the retinal Schiff base is also located in this frequency region. In fact, broad negative feature in the 1660-1650 $\mathrm{cm}^{-1}$ region in $\mathrm{H}_{2} \mathrm{O}$ (dotted line in Figure 3(a)) is reduced in $\mathrm{D}_{2} \mathrm{O}$ (dotted line in Figure 3(b)), by shifting to $1633 \mathrm{~cm}^{-1}$. In the presence of $p H t r I I$, new negative and positive peaks appear at 1663 and $1671 \mathrm{~cm}^{-1}$, respectively, in $\mathrm{H}_{2} \mathrm{O}$, while negative peaks at 1657 and $1651 \mathrm{~cm}^{-1}$ are reduced in amplitude (Figure 3(a)). These observations were repeated in $\mathrm{D}_{2} \mathrm{O}$, though the peaks at $1671(+) / 1663(-) \mathrm{cm}^{-1}$ seem to exist even in the absence of $p$ HtrII (Figure $3(\mathrm{~b})$ ). The $1671(+) / 1663(-) \mathrm{cm}^{-1}$ bands appear in the frequency region typical for the amide-I vibration of $\alpha_{\mathrm{II}}$-helix, while the $1657-\mathrm{cm}^{-1}$ band appears in the range of amide-I vibration of $\alpha_{\mathrm{I}}$-helix [49]. Since $\alpha_{\mathrm{II}}$ -helix possesses considerably distorted structure [50], the present observation suggests that the association of $p \mathrm{pR}$ and $p \mathrm{HtrII}$ yields distortion of the helical structure that is altered by the retinal photoisomerization. The identical spectra for the complex of the unlabeled $p \mathrm{pR}$ and ${ }^{13} \mathrm{C}$ - or ${ }^{15} \mathrm{~N}$-labeled 


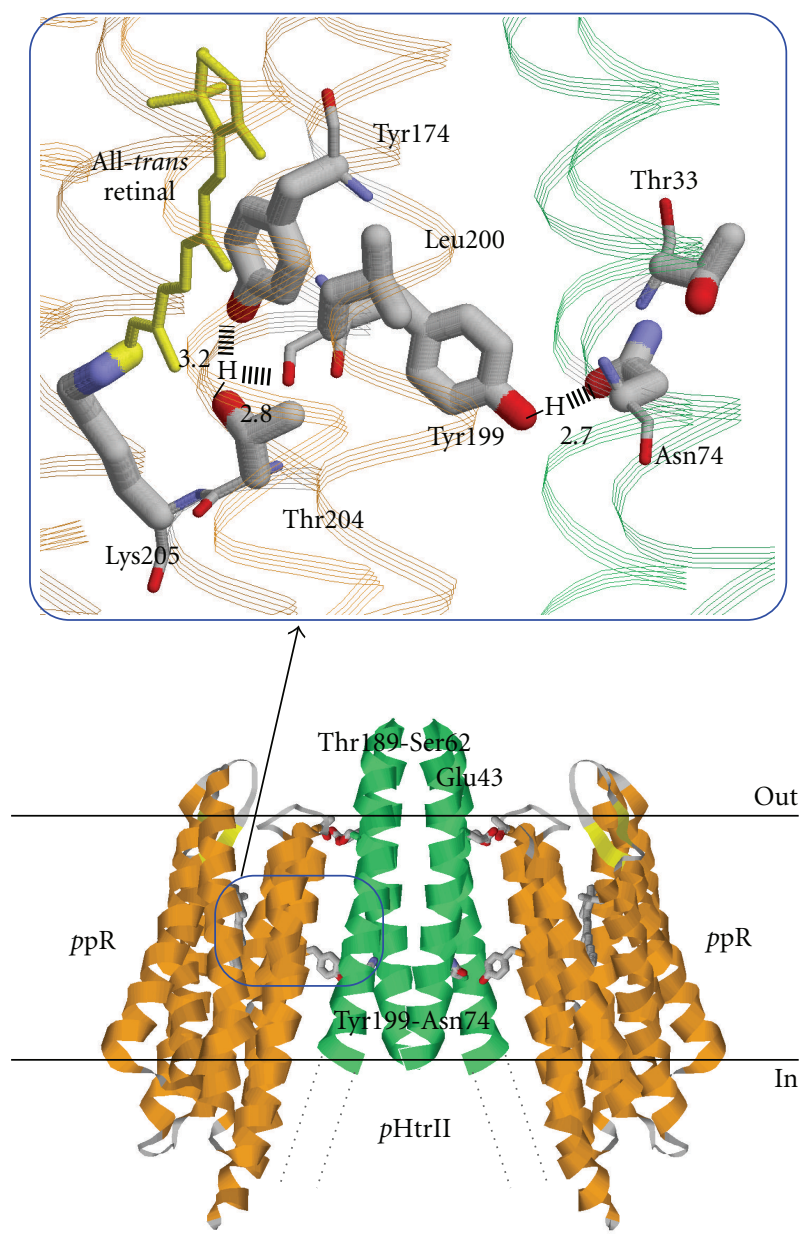

FIgURe 2: (The upper region) X-ray crystallographic structure of the complex between $p \mathrm{pR}$ and $p \mathrm{HtrII}$ (PDB code, 1H2S) [29]. (The lower panel) Details of the X-ray crystallographic structure of the $p \mathrm{pR} / p$ HtrII complex [29] focusing on specific hydrogen bonds. Hydrogen bond between Tyr 199 of $p \mathrm{pR}$ and Asn74 of $p \mathrm{HtrII}$, whose distance is $2.7 \AA$, and hydrogen bond between Tyr174 and Thr204 in $p$ HtrII, whose distance is $3.2 \AA$, are shown. (F) and (G) helices of $p \mathrm{pR}$ that involve Tyr174 and Thr204, respectively, are sandwiched by the retinal chromophore and TM1 and TM2 helices of $p$ HtrII.

$p \mathrm{HtrII}$ indicate that the observed structural changes for the peptide backbone originate from $p$ pR [13]. Namely, by use of isotope label of $p H$ trII, we excluded the possibility that the light signal is transmitted from $p \mathrm{pR}$ to $p \mathrm{HtrII}$ in the $\mathrm{K}$ intermediate [13].

Beside the signal from peptide backbone, clear difference was observed in higher frequency region. Figure 4(a) shows the negative $3479 \mathrm{~cm}^{-1}$ and positive $3369 \mathrm{~cm}^{-1}$ bands only in the presence of $p \mathrm{HtrII}$. These frequencies are considerably higher than the amide-A vibrations $(\mathrm{N}-\mathrm{H}$ stretch of peptide backbone). Therefore, either $\mathrm{N}-\mathrm{H}$ or $\mathrm{O}-\mathrm{H}$ stretching vibration of an amino acid side chain is likely to undergo hydrogen-bonding alteration upon retinal photoisomerization. This group is $\mathrm{H}-\mathrm{D}$ unexchangeable, and it seems that the hydrogen bond is strengthened so as to exhibit frequency

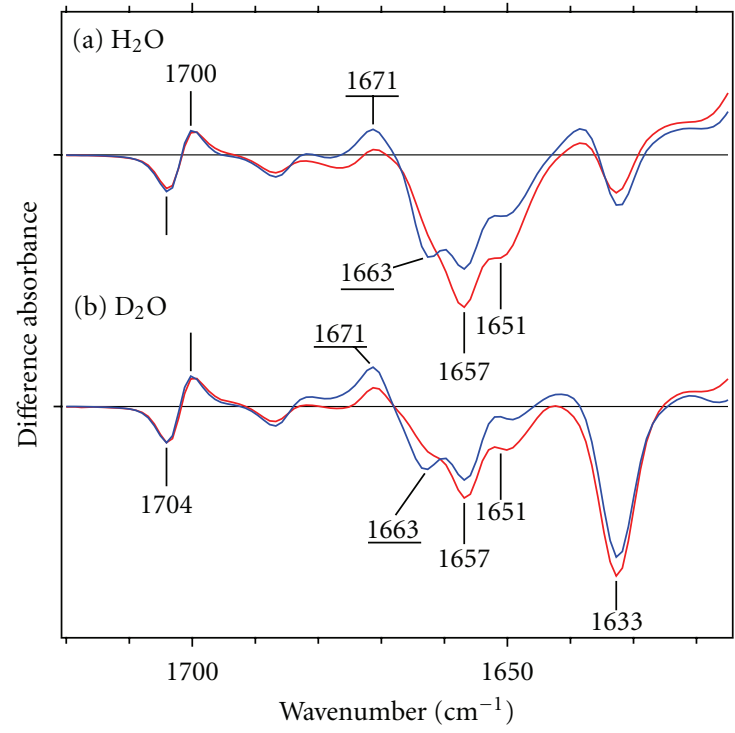

FIGURE 3: $p \mathrm{pR}_{\mathrm{K}}$ minus $p \mathrm{pR}$ infrared difference spectra in the absence (red line) and presence (blue line) of the transducer protein, $p$ HtrII, in the $1720-1615 \mathrm{~cm}^{-1}$ region. Spectra are measured at $77 \mathrm{~K}$ and $\mathrm{pH} 7$ upon hydration with $\mathrm{H}_{2} \mathrm{O}$ (a) and $\mathrm{D}_{2} \mathrm{O}$ (b). The original data appeared in [13].

downshift by about $100 \mathrm{~cm}^{-1}$. The structure of $p p R$ suggests that the bands may originate from $\mathrm{O}-\mathrm{H}$ stretch of Tyr199, Tyr174, or Thr204 (Figure 2). We thereby attempted to assign the vibrational bands by use of mutant proteins such as Y199F, Y174F, T204A, and T204S [20]. We found that the M-decay kinetics of all mutants were delayed in the presence of $p$ HtrII (data not shown), confirming the complex formation in these mutant proteins. Figure 4(b) shows identical spectra between Y199F and the wild type in the $3600-3300 \mathrm{~cm}^{-1}$ region, indicating that these bands do not originate from an $\mathrm{O}-\mathrm{H}$ stretching vibration of Tyr 199. In contrast, the spectra look very different for Y174F, not only in the high-frequency region (Figure 4(c)), but also in the entire mid-infrared region. It should be noted that the negative band at $3430 \mathrm{~cm}^{-1}$ in Y174F looks similar to that at $3479 \mathrm{~cm}^{-1}$ Our previous reports on bacteriorhodopsin and bovine rhodopsin showed that there is a limited number of vibrational bands that appear in the $>3400 \mathrm{~cm}^{-1}$ region in $\mathrm{D}_{2} \mathrm{O}$ for the photoreactions at $77 \mathrm{~K}[51,52]$. Therefore, it is possible that the negative $3479-\mathrm{cm}^{-1}$ band in the wild type is shifted to $3430 \mathrm{~cm}^{-1}$ in Y174F. If it is, the corresponding positive band may be at $3402 \mathrm{~cm}^{-1}$, suggesting that the bands at $3479(-) / 3369(+) \mathrm{cm}^{-1}$ do not originate from the $\mathrm{O}-$ $\mathrm{H}$ stretching vibration of Tyr174. Thus, multiple spectral differences of Y174F made it difficult to conclude if the bands originate from the $\mathrm{O}-\mathrm{H}$ stretch of Tyr174 or not, whereas the mutation of Tyr174 clearly influences the bands.

On the other hand, the results for the mutants of Thr204 led to identification of the bands. Figure 4(d) shows that both $3479(-)$ and $3369(+) \mathrm{cm}^{-1}$ bands disappear in T204A. Disappearance of the $3479(-)$ and $3369(+) \mathrm{cm}^{-1}$ bands was also observed in T204S, whereas new bands appeared at $3498(-)$ and $3474(+) \mathrm{cm}^{-1}$ (Figure 4(e)). 


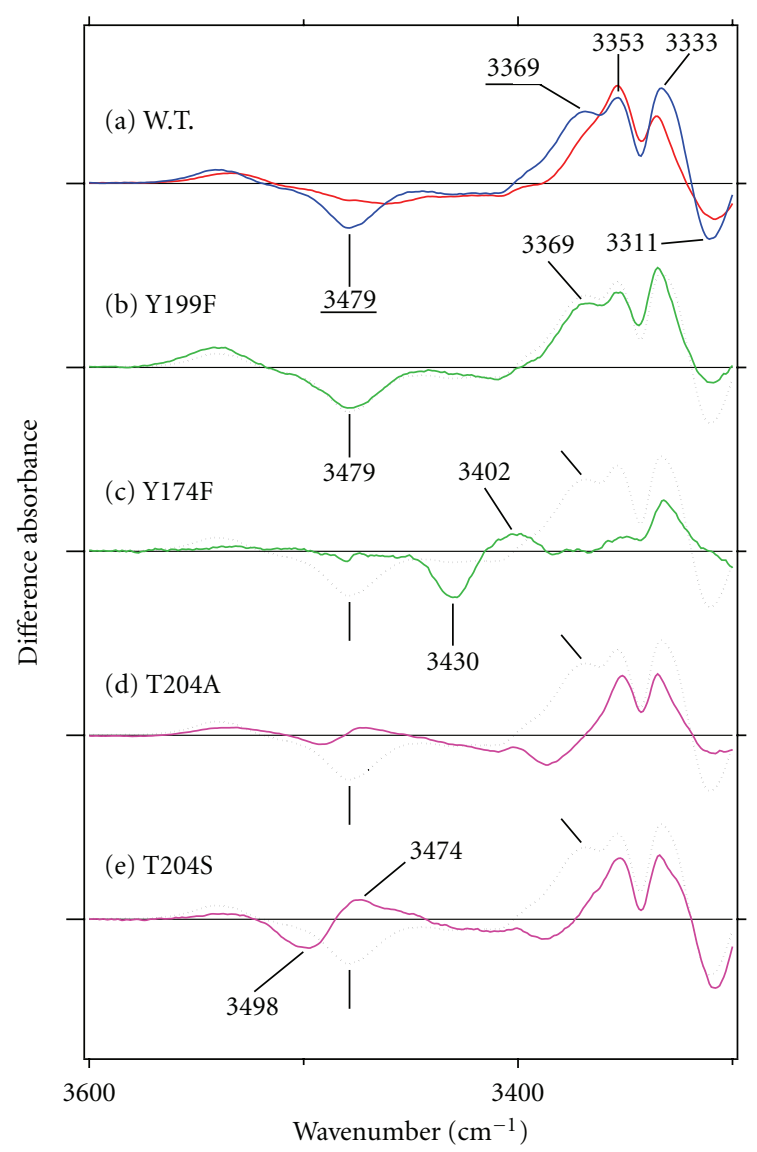

Figure 4: (a) $p \mathrm{pR}_{\mathrm{K}}$ minus $p \mathrm{pR}$ infrared difference spectra in the absence (red line) and presence (blue line) of the transducer protein, $p$ HtrII, in the $3600-3300 \mathrm{~cm}^{-1}$ region. Spectra are measured at $77 \mathrm{~K}$ and $\mathrm{pH} 7$ upon hydration with $\mathrm{D}_{2} \mathrm{O}$. (b-e) $p \mathrm{pR}_{\mathrm{K}}$ minus $p \mathrm{pR}$ infrared difference spectra of the wild type (black dotted lines) and mutant (solid lines; (b) Y199F, (c) Y174F, (d) T204A, (e) T204S) proteins of $p \mathrm{pR}$ in the presence of $p \mathrm{HtrII}$ in the $3600-3300 \mathrm{~cm}^{-1}$ region. Spectra are measured at $77 \mathrm{~K}$ and $\mathrm{pH} 7$ upon hydration with $\mathrm{D}_{2} \mathrm{O}$. The original data appeared in [20].

Although we have not used isotope labeling of threonine, these observations strongly suggest that the bands at 3479 $(-)$ and $3369(+) \mathrm{cm}^{-1}$ originate from the $\mathrm{O}-\mathrm{H}$ stretch of Thr204. The O-H stretch of Ser204 in T204S should be at 3498 and $3474 \mathrm{~cm}^{-1}$ for $p \mathrm{pR}$ and $p \mathrm{pR}_{\mathrm{K}}$, respectively. Secondary alcohols possess their $\mathrm{O}-\mathrm{H}$ stretches at 3626$3629 \mathrm{~cm}^{-1}$ and $3340-3355 \mathrm{~cm}^{-1}$ in $\mathrm{CCl}_{4}$ solution and in neat liquid, respectively [53]. The $\mathrm{O}-\mathrm{H}$ stretching vibration of threonine is thereby located anywhere from $\sim 3630$ to $3340 \mathrm{~cm}^{-1}$, depending on its hydrogen-bonding conditions. The observed frequency in $p \mathrm{pR}$ at $3479 \mathrm{~cm}^{-1}$ corresponds to moderate hydrogen bonding. Similar $\mathrm{O}-\mathrm{H}$ stretches have been reported for Thr17 $\left(3462 \mathrm{~cm}^{-1}\right)$ in bacteriorhodopsin [51] and Thr118 $\left(3463 \mathrm{~cm}^{-1}\right)$ in bovine rhodopsin [52]. The retinal photoisomerization induces frequency downshift of the O-H stretch of Thr204 by $110 \mathrm{~cm}^{-1}$ in $p$ pR. The observed frequency in $p \mathrm{pR}_{K}$ at $3369 \mathrm{~cm}^{-1}$ is close to the value in neat liquid, indicating that the hydrogen bond is very strong [53]. Similar O-H stretches have been reported for Thr89 in bacteriorhodopsin and Thr79 in $p \mathrm{pR}$, which are $\mathrm{H} / \mathrm{D}$ exchangeable and appear at about $2510 \mathrm{~cm}^{-1}$ as O-D stretches [54, 55].

We have studied hydrogen-bonding alterations of threonine side chains in bacteriorhodopsin, and bovine rhodopsin $[52,55]$. It is particularly important to note that at $77 \mathrm{~K}$ the frequency changes are not large in general, since protein structural changes are very limited. We have reported that the frequency shifts at $77 \mathrm{~K}$ are $18 \mathrm{~cm}^{-1}$ for Thr $17,13 \mathrm{~cm}^{-1}$ for Thr121, and about $60 \mathrm{~cm}^{-1}$ for Thr89 in bacteriorhodopsin [51, 55], and $24 \mathrm{~cm}^{-1}$ for Thr118 in bovine rhodopsin [52]. Accordingly, the present observation of the spectral shift by $110 \mathrm{~cm}^{-1}$ is unique among rhodopsins, implying specific structural change. Complex formation with $p \mathrm{HtrII}$ allows specific hydrogen-bonding alteration of Thr-204 upon formation of $p \mathrm{pR}_{\mathrm{K}}$.

The O-H stretch of Thr204 in the $p \mathrm{pR} / p \mathrm{HtrII}$ complex at $3479 \mathrm{~cm}^{-1}$ corresponds to moderate hydrogen bonding. According to the X-ray crystal structure of the $p \mathrm{pR} / p \mathrm{HtrII}$ complex [29], the hydrogen-bonding distance from the side chain oxygen of Thr-204 is $2.8 \AA$ and $3.2 \AA$ to the peptide carbonyl oxygen of Leu200 and phenolic oxygen of Tyr174, respectively (Figure 2). Presence of such hydrogen-bonding acceptors is consistent with the FTIR observation. Upon retinal photoisomerization, frequency of the $\mathrm{O}-\mathrm{H}$ stretch of Thr204 is lowered by $110 \mathrm{~cm}^{-1}$ in the $p \mathrm{pR}_{K} / p \mathrm{HtrII}$ complex, whereas no such bands were observed in the absence of pHtrII (Figure 4(a)). Why does the O-H group of Thr204 change its hydrogen bonding only in the presence of $p \mathrm{HtrII}$ ? Why not in the absence of $p \mathrm{HtrII}$ ? Interestingly, hydrogenbonding network around Thr204 is essentially similar in the free $p$ pR $[27,28]$ and $p$ pR/pHtrII complex $[14,20]$ not only in the unphotolyzed state but also in the $\mathrm{K}$ intermediate state. The X-ray crystal structures of the $p \mathrm{pR}[27,28]$ and $p \mathrm{pR}_{K}$ $[27,28]$ in the absence of $p \mathrm{HtrII}$ are very similar to those of the former [28, 35] and the latter [35] in the presence of $p \mathrm{HtrII}$, respectively. Actually, there are no changes in distances between Thr204 and Tyr174 (3.3 $\AA$ in ppR and $3.4 \AA$ in $p \mathrm{pR}_{\mathrm{K}}$ ), and between Thr204, and Leu200 (2.9 $\AA$ in $p \mathrm{pR}$ and $\left.p \mathrm{pR}_{\mathrm{K}}\right)[27,28,56]$. Interestingly, there are no changes in the distances in the $p \mathrm{pR} / p \mathrm{HtrII}$ complex as well. The distance between Thr204 and Try174 is $3.2 \AA$ in ppR/pHtrII and $3.1 \AA$ in $p$ pR $/ p H$ trII, while that between Thr204 and Leu200 is $2.9 \AA$ in $p$ pR/pHtrII and $3.0 \AA$ in $p \mathrm{pR}_{\mathrm{K}} / p \mathrm{HtrII}$, respectively [35]. These results suggest that the hydrogenbonding change of Thr204 occurs without evident structural changes of Thr204, Tyr174 and Leu200. The electrostatic interaction change upon the retinal isomerization may alter the direction of the O-H group of Thr204 to be optimal for the hydrogen bond with Tyr174 or Lue200.

Several functionally important roles of Thr204 have been reported so far. Thr204 is an important residue for color tuning of $p \mathrm{pR}$, since $\mathrm{T} 204 \mathrm{~A}$ has a significant red-shifted absorption maximum [57]. Thr204 should be involved in the regulation mechanism of the decay process of $p \mathrm{pR}_{\mathrm{O}}$, because the decay of $p \mathrm{pR}_{\mathrm{O}}$ in a quadruple mutant including T204C or T204S becomes greatly accelerated, similar to that of bacteriorhodopsin [58]. In addition, Klare et al. 
suggested that Thr204 may be important for the creation of bacteriorhodopsin-like functional properties by using a quadruple mutant, which includes T204A [59]. This paper has provided an additional important role of Thr204 in the $p \mathrm{pR} / p \mathrm{HtrII}$ complex. Specific interaction in the complex that involves Thr204 presumably affects the decay kinetics and binding affinity in the $\mathrm{M}$-intermediate. In addition, an unexpected finding was gained on the functional correlation about the role of Thr204, which is described below.

\section{Light-Signal Conversion in the Early M-State}

Association between $p \mathrm{pR}$ and $p \mathrm{HtrII}$ is about 100 -times weaker in $p \mathrm{pR}_{\mathrm{M}}$ than in the unphotolyzed state $[26,42]$, indicating that signal transduction from $p \mathrm{pR}$ to $p \mathrm{HtrII}$ involves weakening of their interaction in $\mathrm{M}$. In addition to the intramolecular structural changes of $p \mathrm{pR}$, specific change in the association between $p p R$ and $p H$ trII is expected. In fact, Wegener et al., proposed a rotational motion of TM2 of $p$ HtrII upon excitation of $p \mathrm{pR}$ on the basis of their spin-label experiments [60]. How are such structural changes reflected in the vibrational bands in the FTIR spectra?

After reporting the $p \mathrm{pR}_{\mathrm{M}}$ minus $p \mathrm{pR}$ spectra at $250 \mathrm{~K}$ in 2002 [61] and the $p \mathrm{pR}_{\mathrm{K}}$ minus $p \mathrm{pR}$ spectra of the $p \mathrm{pR} / p \mathrm{HtrII}$ complex at $77 \mathrm{~K}$ in 2003 [13], we then measured the $p p R_{M}$ minus $p \mathrm{pR}$ spectra for the $p \mathrm{pR} / p \mathrm{HtrII}$ complex [21]. The obtained spectra at $250 \mathrm{~K}$ were surprisingly similar between the samples with and without $p H$ trII. This fact suggested that structural changes due to the receptor-transducer interaction are much smaller than those of the receptor itself upon a transition from the resting state $(p p R)$ to the active state $\left(p p R_{M}\right)$. On the other hand, microscopic structural changes do occur in the transducer activation processes of the $p \mathrm{pR} / p \mathrm{HtrII}$ system, which should be probed by highly sensitive infrared measurements, even if they are tiny. Therefore, we carefully examined vibrational bands in $p p R_{M}$ minus $p$ pR spectra of the $p \mathrm{pR} / p$ HtrII complex.

First, we examined the $\mathrm{O}-\mathrm{H}$ signal of Thr204 in the M intermediate. Figure 5(a) shows the $p \mathrm{pR}$ minus $p \mathrm{pR}$ spectra in $\mathrm{D}_{2} \mathrm{O}$, which possess the $3479(-) / 3369(+) \mathrm{cm}^{-1}$ bands only in the presence of $p \mathrm{HtrII}$ [20]. In contrast, the $p \mathrm{pR}_{\mathrm{M}}$ minus $p \mathrm{pR}$ spectra do not possess the $3479(-) / 3369(+)$ $\mathrm{cm}^{-1}$ bands (Figure 5(b)), indicating that the $\mathrm{O}-\mathrm{H}$ group of Thr204 has an identical hydrogen-bonding strength in $p \mathrm{pR}$ and $p \mathrm{pR}_{\mathrm{M}}$. Thus, in the $p \mathrm{pR} / p \mathrm{H}$ trII complex, hydrogen bond of the $\mathrm{O}-\mathrm{H}$ group of $\mathrm{Thr} 204$ is strengthened upon retinal isomerization $\left(p \mathrm{pR}_{\mathrm{K}}\right)$, while being restored upon transducer activation $\left(p \mathrm{p} \mathrm{R}_{\mathrm{M}}\right)$. Local structural perturbation at position 204 is relaxed at the stage of the $\mathrm{M}$ intermediate.

Next, we searched for the spectral difference newly appearing in $p \mathrm{pR}_{\mathrm{M}}$. Since the two spectra with and without pHtrII are very similar (Figures 6(a) and 6(b)), we subtracted the spectrum without $p$ HtrII from that with $p H t r I I$ in $\mathrm{H}_{2} \mathrm{O}$ and $\mathrm{D}_{2} \mathrm{O}$. Consequently, such double difference spectra provided new informative curves with reproducible bands. Figures 6(c) and 6(d) show the double difference spectra in $\mathrm{H}_{2} \mathrm{O}$ and $\mathrm{D}_{2} \mathrm{O}$, respectively. We observed the $1693(-) / 1684$ (+) $\mathrm{cm}^{-1}$ bands in the $1735-1675 \mathrm{~cm}^{-1}$ frequency region. If

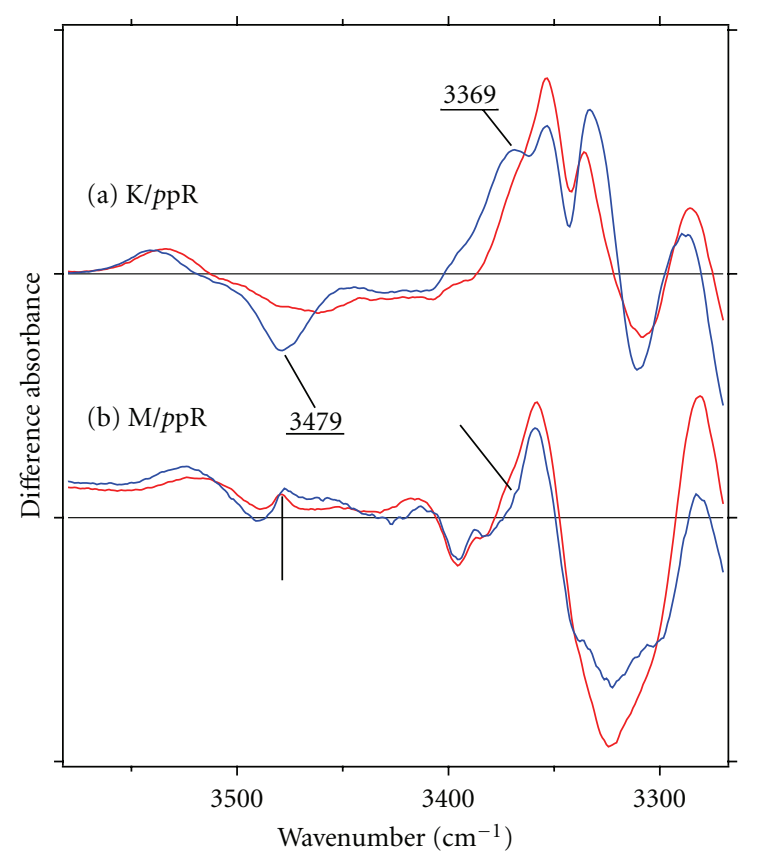

Figure 5: $p \mathrm{pR}_{\mathrm{K}}$ minus $p \mathrm{pR}$ (a) and $p \mathrm{pR}_{\mathrm{M}}$ minus $p \mathrm{pR}$ (b) infrared difference spectra without (red lines) and with (blue lines) $p \mathrm{HtrII}$ in the $3580-3270 \mathrm{~cm}^{-1}$ region. Spectra are measured at $77 \mathrm{~K}$ (a) and $250 \mathrm{~K}$ (b) upon hydration with $\mathrm{D}_{2} \mathrm{O}$. The original data appeared in [21].

the bands originate only from the $p \mathrm{pR} / p \mathrm{HtrII}$ complex, it means that the unphotolyzed $(p \mathrm{pR})$ and $p \mathrm{pR}_{\mathrm{M}}$ states with $p$ HtrII possess vibrational bands at 1693 and $1684 \mathrm{~cm}^{-1}$, respectively. However, analysis of double difference spectra should be done carefully, because tiny differences in amplitudes may lead to apparent bands. In fact, spectral features in the $1710-1700 \mathrm{~cm}^{-1}$ region of Figures $6(\mathrm{c})$ and $6(\mathrm{~d})$ presumably originate from the small difference in amplitude for the $\mathrm{C}=\mathrm{O}$ stretch of Asn105 in ppR (1707 (+)/1701 (-) $\mathrm{cm}^{-1}$ ) [61]. Although the $p \mathrm{pR}_{\mathrm{M}}$ minus $p \mathrm{pR}$ spectra possess a negative band at $1686 \mathrm{~cm}^{-1}$ (Figures 6(a) and 6(b)), the 1693 $(-) / 1684(+) \mathrm{cm}^{-1}$ bands were reproducible for multiple double difference spectra, which were obtained for samples from different preparations. Therefore, we next attempted the following approach under a hypothesis that the 1693 $(-) / 1684(+) \mathrm{cm}^{-1}$ bands originate from the signal due to pHtrII.

In Figures 6(a) and 6(b), the $1707(+) / 1701(-) \mathrm{cm}^{-1}$ bands originate from the $\mathrm{C}=\mathrm{O}$ stretch of Asn 105 in $p \mathrm{pR}$ [61]. Similarly, the negative $1686-\mathrm{cm}^{-1}$ band originates from vibrations in $p \mathrm{pR}$, because it appears in the difference spectrum without $p \mathrm{HtrII}[61]$. As a result of the ${ }^{13} \mathrm{C}$ labeling of $p \mathrm{pR}$, but not $p \mathrm{HtrII}$, these vibrations are expected to downshift by $30-50 \mathrm{~cm}^{-1}$, so that vibrational bands due to pHtrII will appear more clearly. This was indeed the case. Red curves in Figures 6(e) and 6(f) correspond to the $p p R_{M}$ minus $p \mathrm{pR}$ difference spectra for the ${ }^{13} \mathrm{C}$-labeled $p \mathrm{pR}$ in $\mathrm{H}_{2} \mathrm{O}$ and $\mathrm{D}_{2} \mathrm{O}$, respectively, which lack vibrational bands in the $1700-1680 \mathrm{~cm}^{-1}$ region because of the downshifts of the bands at $1707(+), 1701(-)$, and $1686(-) \mathrm{cm}^{-1}$. 
The ${ }^{13} \mathrm{C}=\mathrm{O}$ stretches of Asp75 appear at 1721 and $1711 \mathrm{~cm}^{-1}$ in $\mathrm{H}_{2} \mathrm{O}$ and $\mathrm{D}_{2} \mathrm{O}$, being shifted from 1765 and $1753 \mathrm{~cm}^{-1}$, respectively. Although the presence of $p \mathrm{HtrII}$ does not affect the bands of Asp75, clear effect of $p$ HtrII can be seen in the $1700-1680 \mathrm{~cm}^{-1}$ region (red and blue spectra of Figures 6(e) and 6(f)). Figures 6(e) and 6(f) show the $1693(-) / 1684(+) \mathrm{cm}^{-1}$ bands only in the presence of $p H$ trII, and the frequencies coincide with those of the double difference spectra (Figures 6(c) and 6(d)). This observation strongly suggests that formation of the active $p \mathrm{pR}_{\mathrm{M}}$ state in the complex is accompanied by spectral downshift of a $\mathrm{D}_{2} \mathrm{O}$-insensitive vibrational band of $p \mathrm{HtrII}$ from 1693 to $1684 \mathrm{~cm}^{-1}$.

What is the origin of the band at $1693 \mathrm{~cm}^{-1}$ ? The frequency is characteristic of $\mathrm{C}=\mathrm{O}$ stretch of asparagine or glutamine. Amide-I vibration of $p \mathrm{HtrII}(\mathrm{C}=\mathrm{O}$ stretch of peptide backbone) is another candidate. These two are normally $\mathrm{D}_{2} \mathrm{O}$-insensitive. X-ray structure of the $p \mathrm{pR}-p \mathrm{HtrII}$ complex showed that Asn74 of $p$ HtrII forms hydrogen bond with Tyr 199 of $p \mathrm{pR}$ in the middle of the membrane, while another hydrogen-bonding cluster is formed by Thr189 of $p$ pR, and Glu43/Ser62 of $p$ HtrII at the extracellular surface (Figure 2) [29]. Among these side chains, the $\mathrm{C}=\mathrm{O}$ stretch of Asn74 is the only suitable candidate for the $\mathrm{D}_{2} \mathrm{O}$-insensitive $1693-\mathrm{cm}^{-1}$ band. Therefore, we mutated Asn74 of $p \mathrm{HtrII}$, and measured difference infrared spectra with ${ }^{13} \mathrm{C}$-labeled $p p R$. In this paper, we replaced Asn74 by threonine to keep hydrogen-bonding ability of a residue at the position 74 . In fact, the complex between ${ }^{13} \mathrm{C}$-labeled $p \mathrm{pR}$ and N74T mutant $p H$ trII exhibits two-fold delay of the M-decay kinetics as is the case for the wild type [21], and the $p \mathrm{pR}_{\mathrm{M}}$ minus $p p R$ spectra were almost identical to those of the wild type (data not shown). Nevertheless, clear and reproducible spectral difference was observed in the $1700-1680 \mathrm{~cm}^{-1}$ region. Figure 6 shows that the N74T mutant of $p \mathrm{HtrII}$ lacks the $1693(-) / 1684(+) \mathrm{cm}^{-1}$ bands both in $\mathrm{H}_{2} \mathrm{O}(\mathrm{E})$ and $\mathrm{D}_{2} \mathrm{O}$ (F). Thus, we concluded that the $1693(-) / 1684(+) \mathrm{cm}^{-1}$ bands originate from the $\mathrm{C}=\mathrm{O}$ stretch of Asn74.

Gordeliy et al., reported that the O-H group of Tyr 199 forms a hydrogen bond with the N-H group of Asn74, where Asn74 is the hydrogen-bonding donor [29]. In contrast, the O-H group of Tyr199 forms hydrogen bond with the $\mathrm{C}=\mathrm{O}$ group of Asn74 in the Protein Data Bank structure (1H2S), where Asn74 is the hydrogen-bonding acceptor. It may be reasonable, because nitrogen and oxygen atoms of the side chain of asparagine are not easily distinguishable from X-ray analysis, where hydrogen atoms are invisible. The present paper identified the $\mathrm{C}=\mathrm{O}$ stretch of Asn74 at $1693 \mathrm{~cm}^{-1}$, being about $10 \mathrm{~cm}^{-1}$ lower frequency than that of Asn105 in ppR. It is thus reasonable to suggest that the $\mathrm{C}=\mathrm{O}$ group of Asn 74 forms a hydrogen bond. Since there are no other hydrogen-bonding donors around the $\mathrm{C}=\mathrm{O}$ group of Asn74 [29], it is likely that the O-H group of Tyr199 forms hydrogen bond with the $\mathrm{C}=\mathrm{O}$ group of Asn74 in the complex. The $\mathrm{C}=\mathrm{O}$ stretch frequency is further downshifted by $9 \mathrm{~cm}^{-1}$ in the $\mathrm{M}$ intermediate (Figure 6), indicating that the hydrogen bond has strengthened.

What is the hydrogen-bonding donor of Asn 74 in $p \mathrm{pR}_{\mathrm{M}}$ ? There are alternatives: (i) the $\mathrm{O}-\mathrm{H}$ groups of Tyr199 in $p \mathrm{pR}$, or (ii) other $\mathrm{N}-\mathrm{H}$ or $\mathrm{O}-\mathrm{H}$ group such as Thr33 in $p$ HtrII. In the former case, rearrangement of helices in $p \mathrm{pR}$ and $p \mathrm{HtrII}$ should take place around Tyr199 in $p$ pR and Asn74 in $p$ HtrII. In the latter case, switching of hydrogen-bonding interaction of Asn74 from Tyr199 of $p \mathrm{pR}$ to Thr33 of $p$ HtrII may be directly correlated with the weakened complex association in M. While we did not conclude the origin in the paper [21], Bergo et al., proposed that the interaction between Tyr199 in $p p R$ and Asn74 in pHtrII is disrupted in the $\mathrm{M}$ and $\mathrm{O}$ states [62].

Asn74 forms a hydrogen bond with Tyr199, which belongs to the helix G as well as Thr204 and Lys205 [29]. The O-H group of Thr204 is located at the hydrogenbonding distance from the side-chain oxygen of Tyr174 $(3.2 \AA)$ and the peptide-backbone oxygen of Leu200 (2.8 $\AA$ ). Therefore, retinal photoisomerization induces a structural perturbation in the Lys205/Thr204 region observed in the K intermediate. $\mathrm{M}$ formation is accompanied by a relaxation of the structure at the inner face of the helix G, while the outside of the helix $\mathrm{G}$ is perturbed at position 199. Thus, the present paper revealed one of the pathways in the light-signal transduction, from Lys205 (retinal) of the receptor to Asn74 of the transducer through Thr204 and Tyr199.

\section{Light-Signal Conversion in the Late $M$ State}

The low-temperature FTIR study of the M state revealed the intra- and inter-molecular pathways of light-signal transduction, from Lys205 (retinal) of the receptor to Asn74 of the transducer through Thr204 and Tyr199 [13, $20,21]$. However, these residues are membrane-embedded, while the importance of protein-protein interactions at the cytoplasmic side was still unclear. In fact, previous spinlabeling studies observed the outward tilt of the F-helix in the cytoplasmic region of $p \mathrm{pR}$, which forces rotational motion in $p \mathrm{HtrII}[43,60]$. Therefore, we measured the $p \mathrm{pR}_{\mathrm{M}}$ minus $p \mathrm{pR}$ spectra in the absence and presence of $p \mathrm{HtrII}$ in a wide temperature range of 250-293 K. Figures 7(a) and 7(b) shows the $p \mathrm{pR}_{\mathrm{M}}$ minus $p \mathrm{pR}$ difference spectra in the absence and the presence of $p \mathrm{HtrII}$ at $250-293 \mathrm{~K}$, respectively. In the absence of $p H$ trII, the difference spectra were almost identical to each other, which reproduced the previous observations (Figure 7(a)) [61]. The bands at $1664(-) / 1643$ $(+) \mathrm{cm}^{-1}$ are the largest in the amide-I region, indicating a structural perturbation of $\alpha$ helix. Such structural changes take place for the $\mathrm{M}$ state regardless of temperature between 250 and $293 \mathrm{~K}$.

In contrast, significant temperature dependence was observed for the $p \mathrm{pR} / \mathrm{pH}$ trII complex. Figure $7(\mathrm{~b})$ shows the $p \mathrm{pR}_{\mathrm{M}}$ minus $p \mathrm{pR}$ difference spectra in the presence of $p \mathrm{HtrII}$, where clear spectral variation was seen between different temperatures. In particular, the amide-I vibrations at $1664(-) / 1643(+) \mathrm{cm}^{-1}$ are significantly reduced at higher temperatures, though the peak positions are not changed. At $250 \mathrm{~K}$, the amplitude of the bands at $1664(-) / 1643$ $(+) \mathrm{cm}^{-1}$ is slightly smaller for the $p \mathrm{pR} / p \mathrm{HtrII}$ complex than for $p \mathrm{pR}$ ( $79 \%$ in amplitude). On the other hand, the amplitude of the bands for the $p \mathrm{pR} / \mathrm{pH}$ trII complex is 

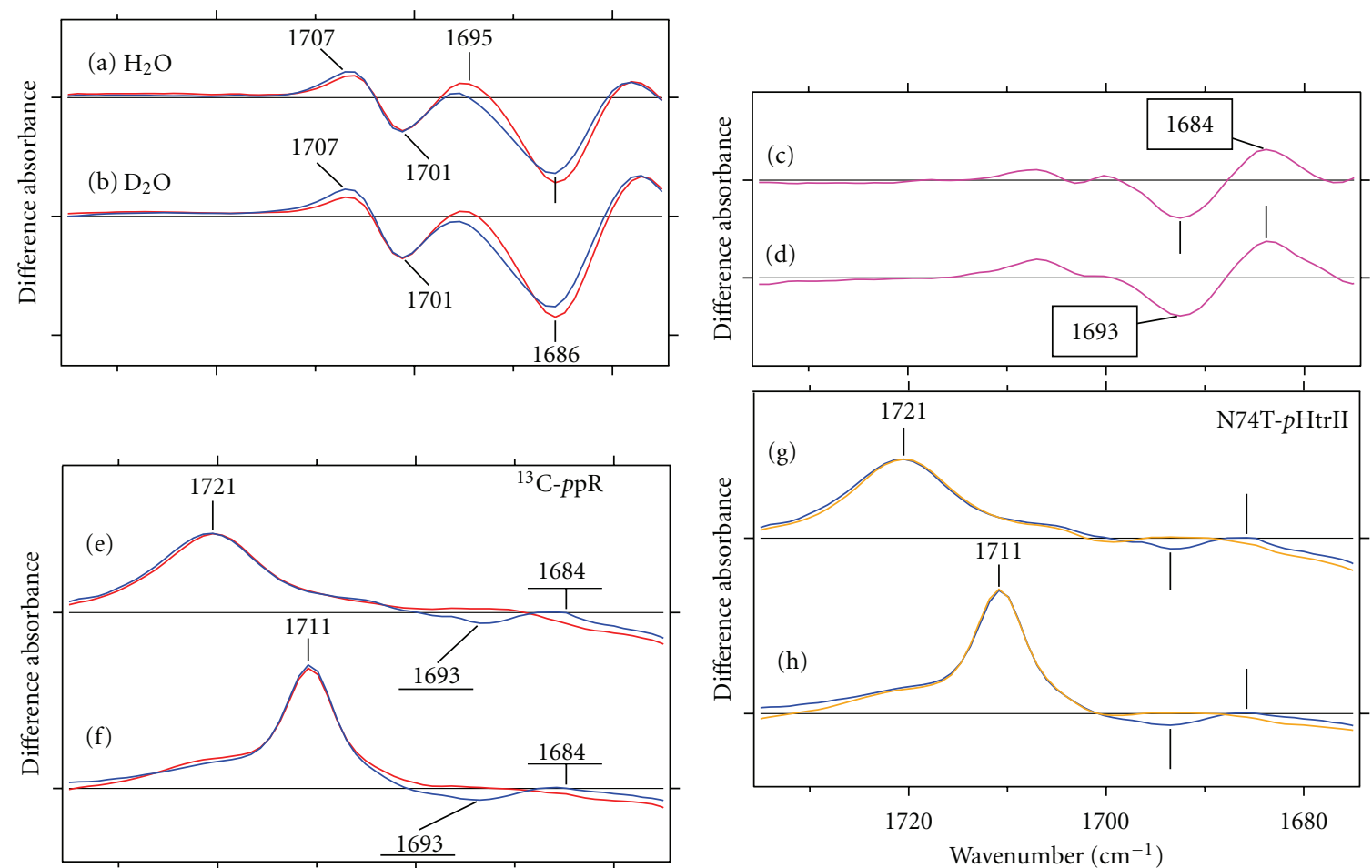

Figure 6: (a) and (b) $p \mathrm{pR}_{\mathrm{M}}$ minus $p \mathrm{pR}$ infrared difference spectra without (red lines) and with (blue lines) $p$ HtrII in the $1735-1675 \mathrm{~cm}^{-1}$ region. Spectra are measured at $250 \mathrm{~K}$ and $\mathrm{pH} 7$ upon hydration with $\mathrm{H}_{2} \mathrm{O}$ (a) and $\mathrm{D}_{2} \mathrm{O}$ (b). One division of the $y$ - that axis corresponds to 0.005 absorbance units. (c) and (d) Double difference spectra obtained from the $p \mathrm{pR}_{\mathrm{M}}$ minus $p \mathrm{pR}$ spectra (a) and (b), where the spectra without $p \mathrm{HtrII}$ were subtracted from those with $p \mathrm{HtrII}$. One division of the $y$ axis corresponds to 0.0018 absorbance units. (e) and (f) $p$ pR $\mathrm{M}_{\mathrm{M}}$ minus $p \mathrm{pR}$ infrared difference spectra for the ${ }^{13} \mathrm{C}$-labeled $p \mathrm{pR}$ without (red lines) and with (blue lines) unlabeled $p \mathrm{HtrII}$. (g) and (h) $p \mathrm{pR} \mathrm{M}_{\mathrm{M}}$ minus $p$ pR infrared difference spectra for the ${ }^{13} \mathrm{C}$-labeled $p \mathrm{pR}$ with unlabeled wild-type (blue lines) and N74T-mutant (orange lines) $p$ HtrII. One division of the $y$ axis corresponds to 0.005 absorbance units. Spectra are measured at $250 \mathrm{~K}$ and $\mathrm{pH} 7$ upon hydration with $\mathrm{H}_{2} \mathrm{O}$ (e, g) and $\mathrm{D}_{2} \mathrm{O}(\mathrm{f}, \mathrm{h})$. The original data appeared in $[21]$.

less than half of that for $p \mathrm{pR}$ at $293 \mathrm{~K}$. Such temperature dependence was also reported by the previous time-resolved FTIR study [63]. Reduction of the bands at $1569(+) / 1545$ $(-) \mathrm{cm}^{-1}$ at room temperature probably originates from the amide-II vibrations [22], which also show structural perturbation of helices. It should be noted that Figure 7 does not contain other spectral components such as from the $\mathrm{O}$ intermediate, because the $p \mathrm{pR}_{\mathrm{O}}$-characteristic band at 1538 $(+) \mathrm{cm}^{-1}[64]$ is missing from the spectra in Figures 7(a) and 7 (b). Fingerprint vibrations at $1300-1100 \mathrm{~cm}^{-1}$ are identical between 250 and $293 \mathrm{~K}$ spectra (data not shown).

This raises an interesting question of the origin of the temperature dependence exclusive for the complex. One possibility is that the amide-I bands of $p \mathrm{pR}$ are influenced by complex formation with $p H$ trII. Alternatively, even when similar amide-I bands of $p \mathrm{pR}$ are preserved in the complex, additional peptide-backbone alterations of $p \mathrm{HtrII}$ may result in the reduction of the total amide-I bands. To resolve this, we examined the origin of the bands by the use of ${ }^{13} \mathrm{C}$-labeled samples [22]. Essentially, the same spectra for ${ }^{12} \mathrm{C}$ - and ${ }^{13} \mathrm{C}$-pHtrII strongly suggest that the temperaturedependent spectral changes originate from $p \mathrm{pR}$, not $p \mathrm{HtrII}$ [22]. It is likely that the protein motions of $p$ pR, particularly at the helices, are somehow perturbed by the presence of $p \mathrm{HtrII}$. Such events take place at room temperature, but are suppressed at low temperatures such as $250 \mathrm{~K}$. Because at $250 \mathrm{~K}$ the water is frozen, the interaction between $p \mathrm{pR}$ and $p$ HtrII may be inhibited at such low temperature.

Temperature dependence of amide-I vibrations of helices is more clearly seen in Figure 7(c), where difference in absorbance between 1643 and $1664 \mathrm{~cm}^{-1}$ is plotted versus temperature. As shown in Figure 7(a), there is no temperature dependence in the absence of $p$ HtrII (filled circles in Figure $7(\mathrm{c})$ ), where the difference is 0.013 absorbance units. In contrast, the amplitude of amide-I vibrations is reduced at high temperatures in the presence of the wildtype $p$ HtrII (filled squares in Figure 7(c)). Amplitude of the amide-I bands exhibits an approximately linear correlation with temperature. A mechanism, by which the secondary structural changes of helices in $p \mathrm{pR}$ are perturbed by the presence of $p H$ trII, is interesting and requires further explanation. Yang et al. that reported that the replacement of Gly83 in pHtrII by cysteine or phenylalanine impairs the photosensory function, indicating the important role of Gly83 in the protein structural changes of the $p \mathrm{pR} / p \mathrm{HtrII}$ complex upon activation [65]. Indeed we found that the temperature dependence of the wild type is lost in the presence of the G83C and G83F mutant $p \mathrm{HtrII}$ 

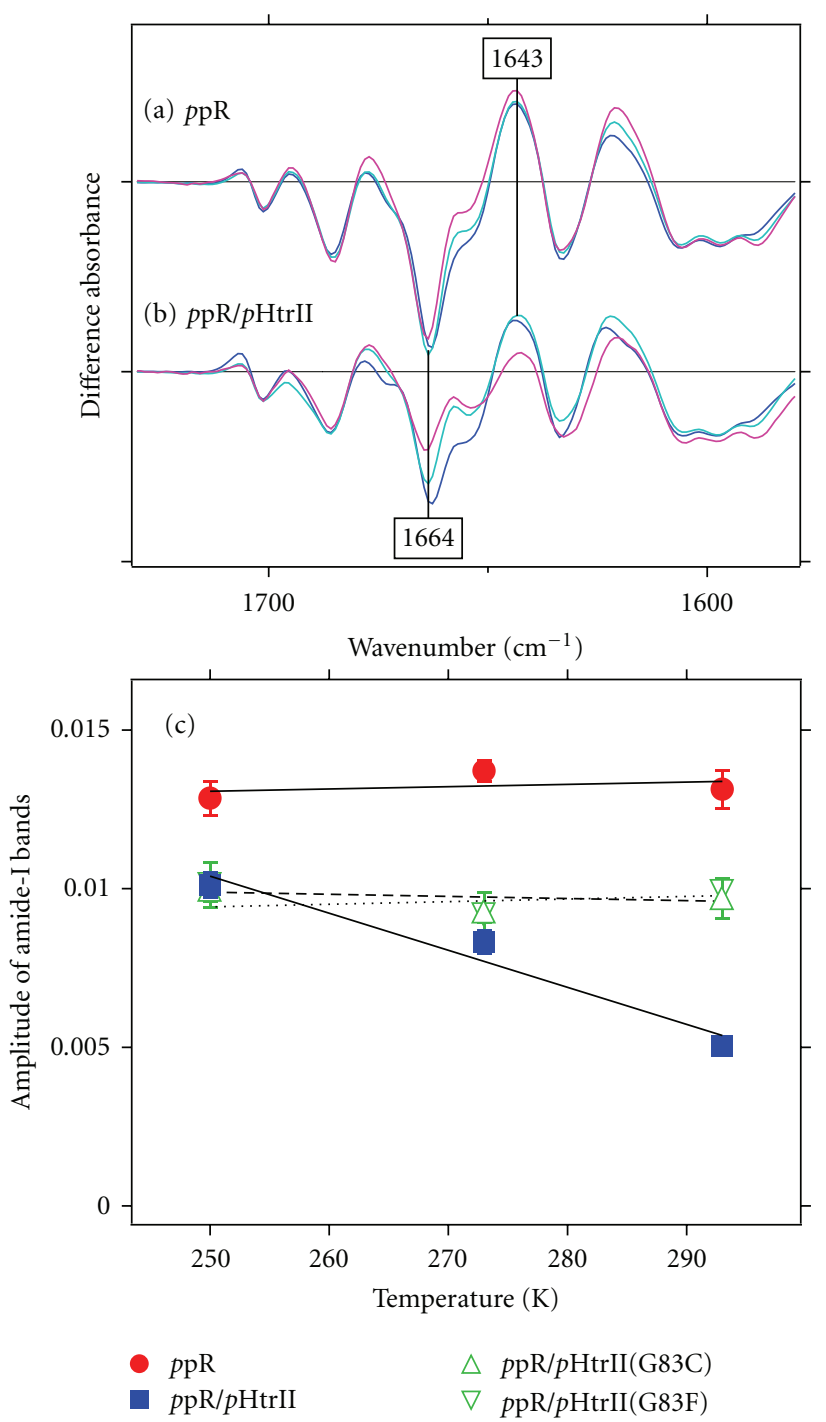

Figure 7: (The upper panel) $p \mathrm{pR}_{\mathrm{M}}$ minus $p \mathrm{pR}$ infrared difference spectra without (a) and with (b) $p H$ trII in the $1730-1520 \mathrm{~cm}^{-1}$ region. Spectra are measured at $250 \mathrm{~K}$ (blue lines), $273 \mathrm{~K}$ (light blue lines), and $293 \mathrm{~K}$ (red lines) upon hydration with $\mathrm{H}_{2} \mathrm{O}$. One division of the $y$ axis corresponds to 0.01 absorbance units. (The lower panel) Temperature dependence of the amplitude of amideI vibrations of helices (c). Difference absorbances between 1643 and $1664 \mathrm{~cm}^{-1}$ are plotted versus temperatures. The original data appeared in [22].

(open triangles in Figure 7(c)), though they form a complex with $p \mathrm{pR}$. The difference is 0.010 absorbance units for all the complexes at $250 \mathrm{~K}$, being considerably smaller than in the absence of $p$ HtrII. While the value is not changed for the G83C and G83F mutant $p$ HtrII, it decreases about twofold for the wild-type $p \mathrm{HtrII}$ at $293 \mathrm{~K}$. These results strongly suggest that Gly83 of $p$ HtrII plays a key role in the helical structural changes of $p \mathrm{pR}$.

Then, how is the temperature dependence of the hydrogen bond of Asn74 of pHtrII? Detailed analysis of the FTIR spectra revealed that the $1694(-) / 1684(+) \mathrm{cm}^{-1}$ bands of Asn74 are not influenced by temperature between
250 and $293 \mathrm{~K}$ [22], suggesting that the hydrogen-bonding alteration of Asn74 observed at $250 \mathrm{~K}$ [21] persists at room temperature. In addition, we also found that mutations of Gly83 do not affect the hydrogen-bonding alteration of Asn74 upon formation of the $M$ state, though the signal transduction is impaired.

The analysis of the $p \mathrm{pR}_{\mathrm{M}}$ minus $p \mathrm{pR}$ difference spectra in a wide temperature range of $250-293 \mathrm{~K}$ provides new insights into the signal transduction mechanism. In the absence of $p \mathrm{HtrII}$, the $p \mathrm{pR}_{\mathrm{M}}$ minus $p \mathrm{pR}$ difference spectra were temperature-independent at 250-293 K, which reproduced the previous results [61]. The largest peak pair in the amide-I region was observed at $1664(-) / 1643(+) \mathrm{cm}^{-1}$, indicating structural perturbation of $\alpha$ helix. Previous spin-labeling study of $p \mathrm{pR}$ observed an outward tilt of the F-helix in the cytoplasmic region $[43,60]$, which also takes place in the light-driven proton-pump protein bacteriorhodopsin (BR) [66]. Thus, the opening of a cleft near the F-helix is presumably common for $p \mathrm{pR}$ and BR. In fact, it is known that $p \mathrm{pR}$ pumps protons in the absence of $p \mathrm{HtrII}$, even though the efficiency is lower than that in BR [41]. Temperatureindependent $p \mathrm{pR}_{\mathrm{M}}$ minus $p \mathrm{pR}$ difference spectra suggest that such cleft opening takes place in a wide temperature range of 250-293 K, though the lack of the $\mathrm{BR}_{\mathrm{N}}$-like amide-I changes for $p \mathrm{pR}[61,67]$ may suggest smaller helical motion in $p \mathrm{pR}$ than in BR.

Interestingly, impairment of the movement of the helix $\mathrm{F}$ of $p \mathrm{pR}$ in the $p \mathrm{pR} / p \mathrm{HtrII}$ complex does not occur (i) at $250 \mathrm{~K}$, or (ii) for the Gly83 mutants of $p H$ trII. Apparently, the opening of a cleft near the helix $\mathrm{F}$ takes place in both cases. In the latter case, disconnection of the two helices at Gly83 may be lost, so that TM2 is extended beyond the position 83 . As a consequence, proper interaction changes do not occur in the cytoplasmic region, and the movement of the helix F takes place. Similar FTIR spectra were obtained for the wild type at $250 \mathrm{~K}$, whereas the hydrogen-bonding alteration of Asn74 in pHtrII was temperature-independent. Therefore, we infer that the structure of the wild-type $p \mathrm{HtrII}$ at $250 \mathrm{~K}$ becomes like that of the Gly83 mutant, and the opening of a cleft near the helix $\mathrm{F}$ takes place in $p \mathrm{pR}$. In this regard, a key issue may be that the linker region is exposed to an aqueous phase, where freezing of water affects the mobility significantly between 250 and $293 \mathrm{~K}$. If it is the case, a straight line between 250 and $293 \mathrm{~K}$ in Figure 7(c) does not describe the temperature dependence properly. Further studies will reveal more detailed mechanism on the signal transduction in the complex.

We discuss the molecular mechanism of protein structural changes in the $p \mathrm{pR} / \mathrm{pHtrII}$ complex by use of schematic drawing of the structure (Figure 8). Gordeliy et al. crystallized $p \mathrm{pR}$ complexed with truncated $p \mathrm{HtrII}$ (residues 1114 ), but the structure of the C-terminal half of $p H t r I I$ (position 83-114) was not determined, presumably because of structural lability [29]. The residues 83-114 are probably located not in the membrane, but in the cytosolic aqueous environment, which may cause structural variations even in a crystal. According to the structure, there are two hydrogen-bonding networks in the transmembrane region of the $p$ pR/pHtrII complex: one between Tyr199 ( $p$ pR) and 


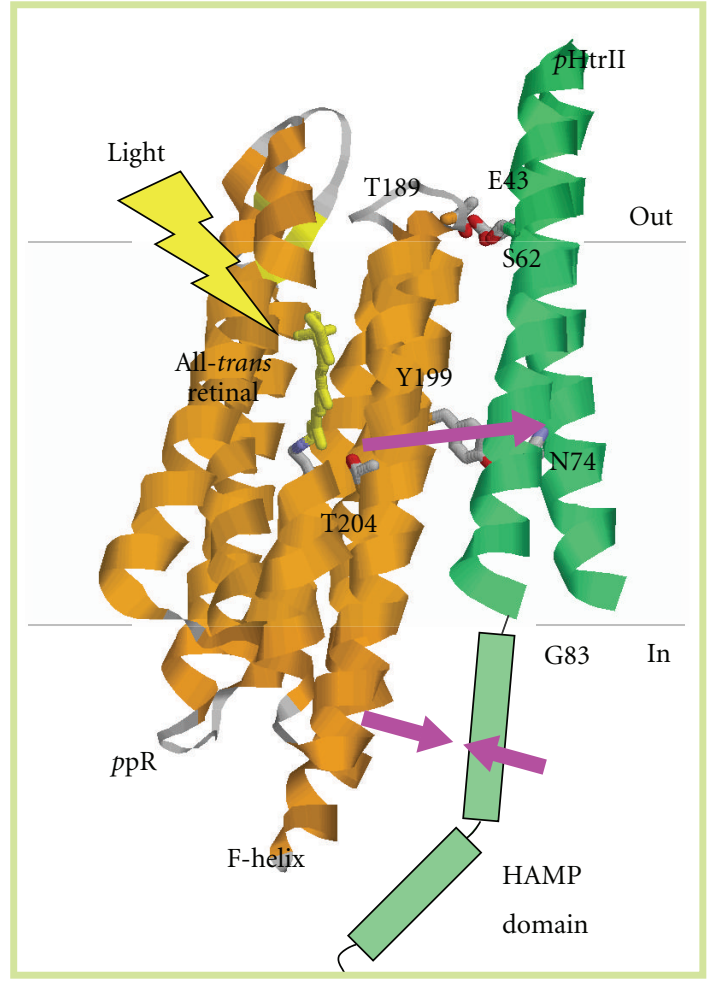

FIGURE 8: Schematic drawing of the signal relay from the receptor $(p \mathrm{pR})$ to the transducer ( $p \mathrm{HtrII})$ in the archaeal photosensory transduction. In the X-ray crystallographic structure of the complex between $p \mathrm{pR}$ (left) and $p \mathrm{HtrII}$ (right) (PDB code, 1H2S) [29], the structure of $p \mathrm{HtrII}$ at position $83-114$ was not determined, suggesting multiple conformations of the region. The association between $p \mathrm{pR}$ and $p \mathrm{HtrII}$ originates mostly from van der Waals contacts in the transmembrane region, whereas Tyr199 and Thr189 of $p \mathrm{pR}$ form hydrogen bonds with Asn74 and Glu43/Ser62 of $p$ HtrII, respectively.

Asn74 ( $p$ HtrII), and the other between Thr189 ( $p$ pR) and Glu43/Ser62 ( $p$ HtrII) (Figure 8). In addition, the interaction of the E-F loop of $p \mathrm{pR}$ and the cytosolic domain of $p \mathrm{HtrII}$ has been suggested [68-70]. These interactions contribute to the strong association of the $p \mathrm{pR} / \mathrm{pH}$ trII complex in the dark (Kd 160 nM [46, 70]).

Then, the light-induced protein structural changes lower the $\mathrm{Kd}$ value by 50 -fold in $\mathrm{ppR}_{\mathrm{M}}(\mathrm{Kd} \sim 5 \mu \mathrm{M}$ [71]). This weakened interaction strongly correlates with the ability for the light-signal transduction. But, what is the origin of the changes in the interaction? Previous FTIR studies revealed the changes in the hydrogen-bonding interaction between Tyr199 of $p \mathrm{pR}$ and Asn74 of $p \mathrm{HtrII}[21,62]$. Additional structural changes have been reported at the cytoplasmic surface of the $p \mathrm{pR} / p \mathrm{HtrII}$ complex. Spin-labeling study observed the outward tilt of the F-helix in $p \mathrm{pR}$, which then forces rotational motion of TM2 in pHtrII $[43,60,68]$. The experiments using FRET and cross linking suggested that the accessibility of the helix $\mathrm{F}$ of $p \mathrm{pR}$ and the linker region of $p$ HtrII decreases upon illumination, and a mutation at the position 83 affects the interaction of these regions [69]. Gly83 presumably functions as a helix breaker together with Gly84, which disconnects transmembrane helix (TM2) from the helical linker region (Figure 8). Structural flexibility at the position 83 is important, because the replacement of Gly83 by cysteine or phenylalanine impairs the signal transduction [65]. Thus, the reduction of the amide-I vibrations of helices at room temperature in the present paper can be interpreted in terms of the impairment of the opening of a cleft near the helix $\mathrm{F}$ by the linker region of $p \mathrm{HtrII}$. It is likely that the Fhelix movement in ppR does not, or only partially, occur in the $p \mathrm{pR} / p \mathrm{HtrII}$ complex, which is manifested as the reduced amide-I vibrations. Such difference must be correlated with the changed permeability of small reagents into the protein interior [72-74]. It should be noted that when the structural changes of $p \mathrm{pR}$ are suppressed by the presence of $p \mathrm{HtrII}$, no additional changes were observed for the amide-I bands in $p$ HtrII. These facts suggest that the signal transduction from the receptor ( $p \mathrm{pR})$ to the transducer ( $p \mathrm{HtrII})$ does not accompany secondary structural alteration of the transducer.

\section{Functional Importance of Thr204 in ppR}

It is now intriguing on the role of the amino acids reported in the FTIR studies. As already shown, mutation of Gly83 in pHtrII (to Cys or Phe) abolishes the photosensory function [65]. On the other hand, Y199F and Y199A mutants of $p \mathrm{pR}$ do not significantly impair the photosensory signaling [69], while the complex formation is remarkably prohibited for the Y199A mutant $[39,46]$. This implies the important role of the Tyr199 ( $p$ pR)-Asn74 ( $p$ HtrII) region in the complex formation, but the hydrogen-bonding interaction between them may not be essential for the signal transduction. Light signal is possibly transferred through the other region.

In 2006, we revealed that T204A, T204S, and Y174F abolish the photosensory function, suggesting the essential role of the hydrogen-bonding interaction between Tyr174 and Thr204 for signaling by the ppR-pHtrII complex [75]. Thr204 is highly conserved in phoborhodopsin, and critical importance of the group is now evident for production of a phototaxis signal. Sudo and Spudich further showed that substitution of a threonine for Ala215 in the proton pump bacteriorhodopsin is sufficient to enable a small but detectable response of $p \mathrm{HtrII}$ [76]. Two additional mutations that align bacteriorhodopsin and $p \mathrm{HtrII}$ in a similar manner as $p \mathrm{pR}$ and $p \mathrm{HtrII}$ enhanced the small response to a robust response comparable to that of the $p \mathrm{pR}-p \mathrm{HtrII}$ complex [76]. The O-H stretching vibration of Thr215 changes its frequency upon the formation of the $\mathrm{K}$ intermediate as similarly as $p \mathrm{pR}$ [77]. It is thereby likely that the hydrogen bond between Tyr174 and Thr204 is essential for the signal relay.

Then, how is the functional importance of the interaction between Tyr174 and Thr204 created? An implication was gained from a novel technique to monitor steric constraint of the retinal chromophore in the binding pocket, where all seven monodeuterated all-trans retinal analogs (positions 7 , $8,10,11,12,14,15)$ were used [78]. The FTIR measurements at $77 \mathrm{~K}$ revealed that only the $\mathrm{C}_{14}-\mathrm{D}$ stretching vibration at $2244 \mathrm{~cm}^{-1}$ is significantly enhanced upon formation of the $\mathrm{K}$ 
state. We interpreted that the steric constraint occurs at the $\mathrm{C}_{14}$-D group in $p \mathrm{pR}_{K}$, where rotation of the $\mathrm{C}_{13}=\mathrm{C}_{14}$ double bond probably leads to the movement of the $\mathrm{C}_{14}-\mathrm{D}$ group [78]. Such steric interaction was also monitored by the $\mathrm{C}_{14^{-}}$ HOOP vibration upon formation of the $p \mathrm{pR}_{K}$ intermediate [79].

The counterpart of the $\mathrm{C}_{14}-\mathrm{D}$ group in $p \mathrm{pR}_{\mathrm{K}}$ is then of interest. According to the X-ray structure of $p \mathrm{pR}$ [27], the distance from the $\mathrm{C}_{14}$ atom is $4.0 \AA$ to the phenol oxygen of Tyr174, $4.4 \AA$ to the hydroxyl oxygen of Thr204, and $4.3 \AA$ to the hydroxyl oxygen of Thr79. The structure of $p \mathrm{pR}_{\mathrm{K}}$ shows that only the distance to Thr204 is significantly reduced, from 4.4 to $3.3 \AA$, by retinal photoisomerization $[27,56]$. This result suggested that Thr204 may be the counterpart of the $\mathrm{C}_{14}-\mathrm{D}$ group, and we indeed identified the counterpart in protein moiety as Thr204 by the use of mutations [80]. Interestingly, we found the correlation between the intensities of the $\mathrm{C}_{14}$-D stretching and $\mathrm{C}_{14}$-HOOP vibrations, and the phototaxis response [80]. Therefore, it was concluded that the specific hydrogen-bonding change of Thr204 is probably caused by the steric hindrance with the $\mathrm{C}_{14}-\mathrm{H}$ group of the retinal chromophore, and the steric constraint between the $\mathrm{C}_{14}-\mathrm{H}$ group of retinal and $\mathrm{Thr} 204$ of the protein is a prerequisite for light-signal transduction by $p \mathrm{pR}$.

\section{Conclusion}

Low-temperature Fourier-transform infrared (FTIR) spectroscopy revealed how light-signal is converted from $p \mathrm{pR}$ to pHtrII, both of which form a complex in the unphotolyzed state. Retinal isomerization strengthens hydrogen bond of the $\mathrm{O}-\mathrm{H}$ group of Thr204 in $p \mathrm{pR}$, which takes place only in the presence of $p H$ trII. Such structural perturbation is restored in the $\mathrm{M}$ intermediate, while the hydrogen bond of Asn74 in $p \mathrm{HtrII}$ is altered. Temperature dependence on the amide-I vibration in $p$ pR suggests the presence of multiple $\mathrm{M}$ states during the activation process, which is disrupted by the mutation of Gly83 in pHtrII. This suggests the importance of dynamical motion of the cytoplasmic domain in the protein-protein interaction. We established the two pathways of light-signal conversion from the receptor to the transducer; (i) from Lys205 (retinal) of ppR to Asn74 of pHtrII through Thr204 and Tyr199, and (ii) from Lys205 of $p \mathrm{pR}$ to the cytoplasmic loop region of $p \mathrm{HtrII}$ that links Gly83 (Figure 8). It should be noted that time-resolved FTIR study was also reported by Bergo et al. in 2003 [63] and 2005 [62], which provided essentially similar information on the protein structural changes in the complex. Thus, FTIR spectroscopy provided fruitful information on the protein structural changes.

Following determination of the X-ray crystallographic structure of the $p \mathrm{pR} / p \mathrm{HtrII}$ complex [29], the intermediate structures of the complex were recently reported for the $\mathrm{K}$ and $\mathrm{M}$ intermediates [35]. Very little structural changes were observed between the $\mathrm{K}$ and unphotolyzed state [35], which was also the case for the uncomplexed $p \mathrm{pR}$ [56]. In contrast, several structural alterations were observed for the $\mathrm{M}$ intermediate [35]. Interestingly, opening of F-helix was not observed [35], which might contradict with the results of the spin-labeled EPR study $[25,43,60]$. However, as shown in our FTIR study, movement of the F-helix opening is probably impaired in the complex, whose extent may depend on the sample conditions. Protein-protein interaction in the cytoplasmic aqueous phase must play important role in the signal transduction. As seen in this paper, light-induced difference FTIR spectroscopy is a powerful tool to investigate the protein-protein interaction and its transient changes for an archaeal light-signal transduction. Together with Xray crystallographic structures and theoretical calculations, better understanding of the transient changes of the proteinprotein complexes will be gained.

\section{Abbreviations}

ppR: pharaonis phoborhodopsin

pHtrII: truncated pharaonis halobacterial transducer II expressed from 1st to 159th position

$p p R_{\mathrm{K}}: \quad$ K-intermediate of $p \mathrm{pR}$

$p \mathrm{pR}_{\mathrm{M}}$ : M-intermediate of $p \mathrm{pR}$

BR: light-adapted bacteriorhodopsin that has all-trans retinal as its chromophore

SRI: Sensory rhodopsin I

FTIR: Fourier-transform infrared

DM: $\quad n$-dodecyl- $\beta$-D-maltoside.

\section{Acknowledgments}

The authors sincerely thank Professor Naoki Kamo for long standing collaboration on the $p \mathrm{pR}$ study. The authors also thank Professors. John L. Spudich, Michio Homma, and Akimori Wada for the interaction study of the $\mathrm{C}_{14}-\mathrm{H}$ group of retinal and Thr204. They thank Drs. Kazumi Shimono, Masayuki Iwamoto Takashi Okitsu, Mr. Kentaro Kamada, and Motohiro Ito for the FTIR experiments. This paper was supported by grants from Japanese ministry of education, Culture, Sports, Science, and Technology to Yuji Furutani, Yuki Sudo, and Hideki Kandori.

\section{References}

[1] Y. Shichida and H. Imai, "Visual pigment: g-protein-coupled receptor for light signals," Cellular and Molecular Life Sciences, vol. 54, no. 12, pp. 1299-1315, 1998.

[2] H. Kandori, Y. Shichida, and T. Yoshizawa, "Photoisomerization in rhodopsin," Biochemistry, vol. 66, no. 11, pp. 11971209, 2001.

[3] T. P. Sakmar, S. T. Menon, E. P. Marin, and E. S. Awad, "Rhodopsin: insights from recent structural studies," Annual Review of Biophysics and Biomolecular Structure, vol. 31, pp. 443-484, 2002.

[4] J. Sasaki and J. L. Spudich, "Proton transport by sensory rhodopsins and its modulation by transducer- binding," Biochimica et Biophysica Acta, vol. 1460, no. 1, pp. 230-239, 2000.

[5] N. Kamo, K. Shimono, M. Iwamoto, and Y. Sudo, "Photochemistry and photoinduced proton-transfer by pharaonis phoborhodopsin," Biochemistry, vol. 66, no. 11, pp. 1277$1282,2001$. 
[6] T. P. Sakmar, "Structure of rhodopsin and the superfamily of seven-helical receptors: the same and not the same," Current Opinion in Cell Biology, vol. 14, no. 2, pp. 189-195, 2002.

[7] Y. Shichida and T. Yamashita, "Diversity of visual pigments from the viewpoint of $G$ protein activation-comparison with other G protein-coupled receptors," Photochemical and Photobiological Sciences, vol. 2, no. 12, pp. 1237-1246, 2003.

[8] K. J. Rothschild, "FTIR difference spectroscopy of bacteriorhodopsin: toward a molecular model," Journal of Bioenergetics and Biomembranes, vol. 24, no. 2, pp. 147-167, 1992.

[9] F. Siebert, "Infrared spectroscopy applied to biochemical and biological problems," Methods in Enzymology, vol. 246, pp. 501-526, 1995.

[10] K. Gerwert, "Molecular reaction mechanisms of proteins monitored by time-resolved FTIR-Spectroscopy," Biological Chemistry, vol. 380, no. 7-8, pp. 931-935, 1999.

[11] J. Heberle, "Proton transfer reactions across bacteriorhodopsin and along the membrane," Biochimica et Biophysica Acta, vol. 1458, no. 1, pp. 135-147, 2000.

[12] S. Nishimura, J. Sasaki, H. Kandori, T. Matsuda, Y. Fukada, and A. Maeda, "Structural changes in the peptide backbone in complex formation between activated rhodopsin and transducin studied by FTIR spectroscopy," Biochemistry, vol. 35, no. 41, pp. 13267-13271, 1996.

[13] Y. Furutani, Y. Sudo, N. Kamo, and H. Kandori, "FTIR spectroscopy of the complex between pharaonis phoborhodopsin and its transducer protein," Biochemistry, vol. 42, no. 17, pp. 4837-4842, 2003.

[14] H. Kandori, "Role of internal water molecules in bacteriorhodopsin," Biochimica et Biophysica Acta, vol. 1460, no. 1, pp. 177-191, 2000.

[15] Y. Furutani and H. Kandori, "Internal water molecules of archaeal rhodopsins," Molecular Membrane Biology, vol. 19, no. 4, pp. 257-265, 2002.

[16] H. Kandori, "Hydration switch model for the proton transfer in the Schiff base region of bacteriorhodopsin," Biochimica et Biophysica Acta, vol. 1658, no. 1-2, pp. 72-79, 2004.

[17] Y. Furutani, M. Shibata, and H. Kandori, "Strongly hydrogenbonded water molecules in the Schiff base region of rhodopsins," Photochemical and Photobiological Sciences, vol. 4, no. 9, pp. 661-666, 2005.

[18] H. Kandori, "Retinal binding protein," in Cis-Trans Isomerization in Biochemistry, C. Dugave, Ed., pp. 53-75, Wiley-VCH, Freiburg, Germany, 2006.

[19] H. Kandori, K. Shimono, Y. Sudo, M. Iwamoto, Y. Shichida, and N. Kamo, "Structural changes of pharaonis phoborhodopsin upon photoisomerization of the retinal chromophore: infrared spectral comparison with bacteriorhodopsin," Biochemistry, vol. 40, no. 31, pp. 9238-9246, 2001.

[20] Y. Sudo, Y. Furutani, K. Shimono, N. Kamo, and H. Kandori, "Hydrogen bonding alteration of Thr-204 in the complex between pharaonis phoborhodopsin and its transducer protein," Biochemistry, vol. 42, no. 48, pp. 14166-14172, 2003.

[21] Y. Furutani, K. Kamada, Y. Sudo, K. Shimono, N. Kamo, and H. Kandori, "Structural changes of the complex between pharaonis phoborhodopsin and its cognate transducer upon formation of the M photointermediate," Biochemistry, vol. 44, no. 8, pp. 2909-2915, 2005.

[22] K. Kamada, Y. Furutani, Y. Sudo, N. Kamo, and H. Kandori, "Temperature-dependent interactions between photoactivated pharaonis phoborhodopsin and its transducer," Biochemistry, vol. 45, no. 15, pp. 4859-4866, 2006.
[23] E. Pebay-Peyroula, A. Royant, E. M. Landau, and J. Navarro, "Structural basis for sensory rhodopsin function," Biochimica et Biophysica Acta, vol. 1565, no. 2, pp. 196-205, 2002.

[24] J. L. Spudich and H. Luecke, "Sensory rhodopsin II: functional insights from structure," Current Opinion in Structural Biology, vol. 12, no. 4, pp. 540-546, 2002.

[25] J. P. Klare, V. I. Gordeliy, J. Labahn, G. Büldt, H.-J. Steinhoff, and M. Engelhard, "The archaeal sensory rhodopsin II/transducer complex: a model for transmembrane signal transfer," FEBS Letters, vol. 564, no. 3, pp. 219-224, 2004.

[26] Y. Sudo, H. Kandori, and N. Kamo, Recent Research Developments in Biophysics, vol. 3, pp. 1-16, 2004.

[27] H. Luecke, B. Schobert, J. K. Lanyi, E. N. Spudich, and J. L. Spudich, "Crystal structure of sensory rhodopsin II at 2.4 angstroms: insights into color tuning and transducer interaction," Science, vol. 293, no. 5534, pp. 1499-1503, 2001.

[28] A. Royant, P. Nollert, K. Edman, et al., "X-ray structure of sensory rhodopsin II at 2.1- $\AA$ resolution," Proceedings of the National Academy of Sciences of the United States of America, vol. 98, no. 18, pp. 10131-10136, 2001.

[29] V. I. Gordeliy, J. Labahn, R. Moukhametzianov, et al., "Molecular basis of transmembrane signalling by sensory rhodopsin II-transducer complex," Nature, vol. 419, no. 6906, pp. 484487, 2002.

[30] J. Rudolph, B. Nordmann, K.-F. Storch, H. Gruenberg, K. Rodewald, and D. Oesterhelt, "A family of halobacterial transducer proteins," FEMS Microbiology Letters, vol. 139, no. 2-3, pp. 161-168, 1996.

[31] J. J. Falke, R. B. Bass, S. L. Butler, S. A. Chervitz, and M. A. Danielson, "The two-component signaling pathway of bacterial chemotaxis: a molecular view of signal transduction by receptors, kinases, and adaptation enzymes," Annual Review of Cell and Developmental Biology, vol. 13, pp. 457-512, 1997.

[32] M. R. K. Alley, J. R. Maddock, and L. Shapiro, "Requirement of the carboxyl terminus of a bacterial chemoreceptor for its targeted proteolysis," Science, vol. 259, no. 5102, pp. 17541757, 1993.

[33] J. R. Maddock and L. Shapiro, "Polar location of the chemoreceptor complex in the Escherichia coli cell," Science, vol. 259, no. 5102, pp. 1717-1723, 1993.

[34] J. Rudolph and D. Oesterhelt, "Deletion analysis of the che operon in the archaeon Halobacterium salinarium," Journal of Molecular Biology, vol. 258, no. 4, pp. 548-554, 1996.

[35] R. Moukhametzianov, J. P. Klare, R. Efremov, et al., "Development of the signal in sensory rhodopsin and its transfer to the cognate transducer," Nature, vol. 440, no. 7080, pp. 115-119, 2006.

[36] X.-N. Zhang, J. Zhu, and J. L. Spudich, "The specificity of interaction of archaeal transducers with their cognate sensory rhodopsins is determined by their transmembrane helices," Proceedings of the National Academy of Sciences of the United States of America, vol. 96, no. 3, pp. 857-862, 1999.

[37] H. Kandori, H. Tomioka, and H. Sasabe, "Excited-state dynamics of pharaonis phoborhodopsin probed by femtosecond fluorescence spectroscopy," Journal of Physical Chemistry A, vol. 106, no. 10, pp. 2091-2095, 2002.

[38] B. Yan, T. Takahashi, R. Johnson, and J. L. Spudich, "Identification of signaling states of a sensory receptor by modulation of lifetimes of stimulus-induced conformations: the case of sensory rhodopsin II," Biochemistry, vol. 30, no. 44, pp. 1068610692, 1991.

[39] Y. Sudo, M. Yamabi, M. Iwamoto, K. Shimono, and N. Kamo, "Interaction of natronobacterium pharaonis phoborhodopsin (sensory rhodopsin II) with its cognate transducer probed 
by increase in the thermal stability," Photochemistry and Photobiology, vol. 78, no. 5, pp. 511-516, 2003.

[40] K. Shimono, M. Iwamoto, M. Sumi, and N. Kamo, "Functional expression of pharaonis phoborhodopsin in Escherichia coli," FEBS Letters, vol. 420, no. 1, pp. 54-56, 1997.

[41] Y. Sudo, M. Iwamoto, K. Shimono, M. Sumi, and N. Kamo, "Photo-induced proton transport of pharaonis phoborhodopsin (sensory rhodopsin II) is ceased by association with the transducer," Biophysical Journal, vol. 80, no. 2, pp. 916-922, 2001.

[42] Y. Sudo, M. Iwamoto, K. Shimono, and N. Kamo, "Pharaonis phoborhodopsin binds to its cognate truncated transducer even in the presence of a detergent with a 1:1 stoichiometry," Photochemistry and Photobiology, vol. 74, no. 3, pp. 489-494, 2001.

[43] A.-A. Wegener, I. Chizhov, M. Engelhard, and H.-J. Steinhoff, "Time-resolved detection of transient movement of helix $\mathrm{F}$ in spin-labelled pharaonis sensory rhodopsin II," Journal of Molecular Biology, vol. 301, no. 4, pp. 881-891, 2000.

[44] Y. Sudo, M. Iwamoto, K. Shimono, and N. Kamo, "Association between a photo-intermediate of a M-lacking mutant D75N of pharaonis phoborhodopsin and its cognate transducer," Journal of Photochemistry and Photobiology B, vol. 67, no. 3, pp. 171-176, 2002.

[45] Y. Sudo, M. Iwamoto, K. Shimono, and N. Kamo, "Tyr199 and charged residues of pharaonis phoborhodopsin are important for the interaction with its transducer," Biophysical Journal, vol. 83, no. 1, pp. 427-432, 2002.

[46] S. Hippler-Mreyen, J. P. Klare, A. A. Wegener, et al., "Probing the sensory rhodopsin II binding domain of its cognate transducer by calorimetry and electrophysiology," Journal of Molecular Biology, vol. 330, no. 5, pp. 1203-1213, 2003.

[47] R. A. Bogomolni, W. Stoeckenius, I. Szundi, E. Perozo, K. D. Olson, and J. L. Spudich, "Removal of transducer HtrI allows electrogenic proton translocation by sensory rhodopsin I," Proceedings of the National Academy of Sciences of the United States of America, vol. 91, no. 21, pp. 10188-10192, 1994.

[48] K. Inoue, J. Sasaki, M. Morisaki, F. Tokunaga, and M. Terazima, "Time-resolved detection of sensory rhodopsin IItransducer interaction," Biophysical Journal, vol. 87, no. 4, pp. 2587-2597, 2004.

[49] S. Krimm and J. Bandekar, "Vibrational spectroscopy and conformation of peptides, polypeptides, and proteins," Advances in Protein Chemistry, vol. 38, pp. 181-364, 1986.

[50] S. Krimm and A. M. Dwivedi, "Infrared spectrum of the purple membrane: clue to a proton conduction mechanism?" Science, vol. 216, no. 4544, pp. 407-708, 1982.

[51] H. Kandori, N. Kinoshita, Y. Yamazaki, et al., "Local and distant protein structural changes on photoisomerization of the retinal in bacteriorhodopsin," Proceedings of the National Academy of Sciences of the United States of America, vol. 97, no. 9, pp. 4643-4648, 2000.

[52] T. Nagata, T. Oura, A. Terakita, H. Kandori, and Y. Shichida, "Isomer-specific interaction of the retinal chromophore with threonine-118 in rhodopsin," Journal of Physical Chemistry A, vol. 106, no. 10, pp. 1969-1975, 2002.

[53] D. Lin-Vien, N. B. Colthup, W. G. Fateley, and J. G. Grasselli, The Handbook of Infrared and Raman Characteristic Frequencies of Organic Molecules, Academic Press, San Diego, Calif, USA, 1991.

[54] K. Shimono, Y. Furutani, N. Kamo, and H. Kandori, "Vibrational modes of the protonated Schiff base in pharaonis phoborhodopsin," Biochemistry, vol. 42, no. 25, pp. 78017806, 2003.
[55] H. Kandori, N. Kinoshita, Y. Yamazaki, et al., "Structural change of threonine 89 upon photoisomerization in bacteriorhodopsin as revealed by polarized FTIR spectroscopy," Biochemistry, vol. 38, no. 30, pp. 9676-9683, 1999.

[56] K. Edman, A. Royant, P. Nollert, et al., "Early structural rearrangements in the photocycle of an integral membrane sensory receptor," Structure, vol. 10, no. 4, pp. 473-482, 2002.

[57] K. Shimono, M. Iwamoto, M. Sumi, and N. Kamo, "Effects of three characteristic amino acid residues of pharaonis phoborhodopsin on the absorption maximum," Photochemistry and Photobiology, vol. 72, no. 1, pp. 141-145, 2000.

[58] M. Iwamoto, Y. Sudo, K. Shimono, T. Araiso, and N. Kamo, "Correlation of the o-intermediate rate with the $\mathrm{pKa}$ of Asp75 in the dark, the counterion of the Schiff base of pharaonis phoborhodopsin (sensory rhodopsin II)," Biophysical Journal, vol. 88, no. 2, pp. 1215-1223, 2005.

[59] J. P. Klare, G. Schmies, I. Chizhov, K. Shimono, N. Kamo, and M. Engelhard, "Probing the proton channel and the retinal binding site of Natronobacterium pharaonis sensory rhodopsin II," Biophysical Journal, vol. 82, no. 4, pp. 21562164, 2002.

[60] A.-A. Wegener, J. P. Klare, M. Engelhard, and H.-J. Steinhoff, "Structural insights into the early steps of receptor-transducer signal transfer in archaeal phototaxis," EMBO Journal, vol. 20, no. 19, pp. 5312-5319, 2001.

[61] Y. Furutani, M. Iwamoto, K. Shimono, N. Kamo, and H. Kandori, "FTIR spectroscopy of the M photointermediate in pharaonis phoborhodopsin," Biophysical Journal, vol. 83, no. 6, pp. 3482-3489, 2002.

[62] V. Bergo, E. N. Spudich, K. J. Rothschild, and J. L. Spudich, "Photoactivation perturbs the membrane-embedded contacts between sensory rhodopsin II and its transducer," Journal of Biological Chemistry, vol. 280, no. 31, pp. 28365-28369, 2005.

[63] V. Bergo, E. N. Spudich, J. L. Spudich, and K. J. Rothschild, "Conformational changes detected in a sensory rhodopsin IItransducer complex," Journal of Biological Chemistry, vol. 278, no. 38, pp. 36556-36562, 2003.

[64] Y. Furutani, M. Iwamoto, K. Shimono, et al., "FTIR Spectroscopy of the $\mathrm{O}$ photointermediate in pharaonis phoborhodopsin," Biochemistry, vol. 43, no. 18, pp. 5204-5212, 2004.

[65] C.-S. Yang and J. L. Spudich, "Light-induced structural changes occur in the transmembrane helices of the Natronobacterium pharaonis HtrII transducer," Biochemistry, vol. 40, no. 47, pp. 14207-14214, 2001.

[66] H.-J. Steinhoff, A. Savitsky, C. Wegener, M. Pfeiffer, M. Plato, and K. Möbius, "High-field EPR studies of the structure and conformational changes of site-directed spin labeled bacteriorhodopsin," Biochimica et Biophysica Acta, vol. 1457, no. 3, pp. 253-262, 2000.

[67] H. Kandori, N. Kinoshita, Y. Shichida, A. Maeda, R. Needleman, and J. K. Lanyi, "Cysteine S-H as a hydrogen-bonding probe in proteins," Journal of the American Chemical Society, vol. 120 , no. 23 , pp. 5828-5829, 1998.

[68] E. Bordignon, J. P. Klare, M. Doebber, et al., "Structural analysis of a HAMP domain: the linker region of the phototransducer in complex with sensory rhodopsin II," Journal of Biological Chemistry, vol. 280, no. 46, pp. 38767-38775, 2005.

[69] C.-S. Yang, O. Sineshchekov, E. N. Spudich, and J. L. Spudich, "The cytoplasmic membrane-proximal domain of the HtrII transducer interacts with the E-F loop of photoactivated Natronomonas pharaonis sensory rhodopsin II," Journal of Biological Chemistry, vol. 279, no. 41, pp. 42970-42976, 2004.

[70] Y. Sudo, H. Okuda, M. Yamabi, et al., "Linker region of a halobacterial transducer protein interacts directly with its 
sensor retinal protein," Biochemistry, vol. 44, no. 16, pp. 6144$6152,2005$.

[71] Y. Sudo, T. Nishihori, M. Iwamoto, K. Shimono, C. Kojima, and N. Kamo, "A long-lived M-like state of phoborhodopsin that mimics the active state," Biophysical Journal, vol. 95, no. 2, pp. 753-760, 2008.

[72] U. Zadok, J. P. Klare, M. Engelhard, and M. Sheves, "The hydroxylamine reaction of sensory rhodopsin II: light-induced conformational alterations with $\mathrm{C}_{13} \mathrm{C}_{14}$ nonisomerizable pigment," Biophysical Journal, vol. 89, no. 4, pp. 2610-2617, 2005.

[73] H. Yoshida, Y. Sudo, K. Shimono, M. Iwamoto, and N. Kamo, "Transient movement of helix F revealed by photo-induced inactivation by reaction of a bulky $\mathrm{SH}$-reagent to cysteineintroduced pharaonis phoborhodopsin (sensory rhodopsin II)," Photochemical and Photobiological Sciences, vol. 3, no. 6, pp. 537-542, 2004.

[74] Y. Sudo, M. Iwamoto, K. Shimono, and N. Kamo, "Association of pharaonis phoborhodopsin with its cognate transducer decreases the photo-dependent reactivity by water-soluble reagents of azide and hydroxylamine," Biochimica et Biophysica Acta, vol. 1558, no. 1, pp. 63-69, 2002.

[75] Y. Sudo, Y. Furutani, H. Kandori, and J. L. Spudich, "Functional importance of the interhelical hydrogen bond between $\mathrm{Thr}^{204}$ and $\mathrm{Thr}^{174}$ of sensory rhodopsin II and its alteration during the signaling process," Journal of Biological Chemistry, vol. 281, no. 45, pp. 34239-34245, 2006.

[76] Y. Sudo and J. L. Spudich, "Three strategically placed hydrogen-bonding residues convert a proton pump into a sensory receptor," Proceedings of the National Academy of Sciences of the United States of America, vol. 103, no. 44, pp. 16129-16134, 2006.

[77] Y. Sudo, Y. Furutani, J. L. Spudich, and H. Kandori, "Early photocycle structural changes in a bacteriorhodopsin mutant engineered to transmit photosensory signals," Journal of Biological Chemistry, vol. 282, no. 21, pp. 15550-15558, 2007.

[78] Y. Sudo, Y. Furutani, A. Wada, M. Ito, N. Kamo, and H. Kandori, "Steric constraint in the primary photoproduct of an archaeal rhodopsin from regiospecific perturbation of C-D stretching vibration of the retinyl chromophore," Journal of the American Chemical Society, vol. 127, no. 46, pp. 16036-16037, 2005.

[79] Y. Furutani, Y. Sudo, A. Wada, et al., "Assignment of the hydrogen-out-of-plane and -in-plane vibrations of the retinal chromophore in the $\mathrm{K}$ intermediate of pharaonis phoborhodopsin," Biochemistry, vol. 45, no. 39, pp. 11836-11843, 2006.

[80] M. Ito, Y. Sudo, Y. Furutani, et al., "Steric constraint in the primary photoproduct of sensory rhodopsin II is a prerequisite for light-signal transfer to HtrII," Biochemistry, vol. 47, no. 23, pp. 6208-6215, 2008. 

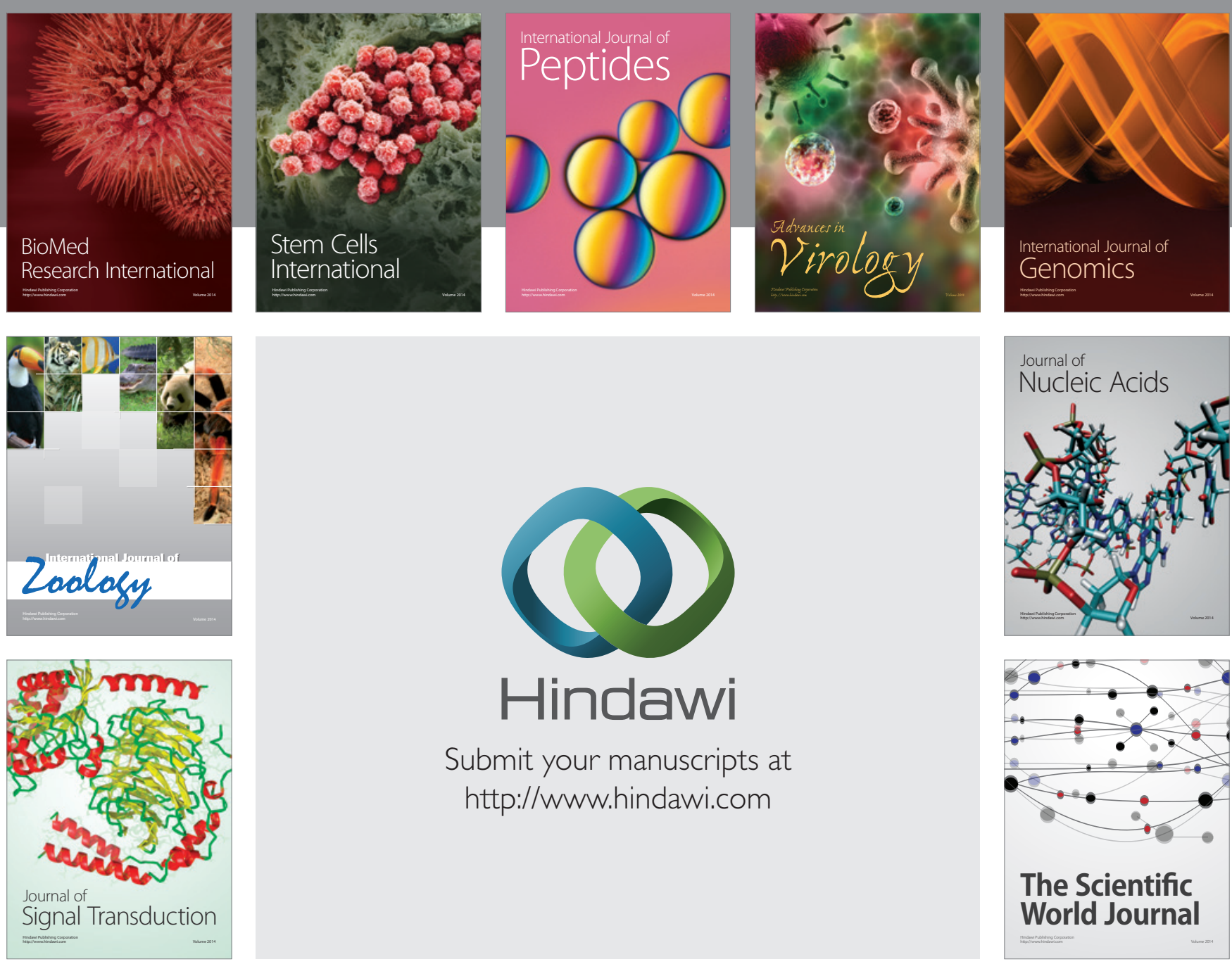

Submit your manuscripts at

http://www.hindawi.com
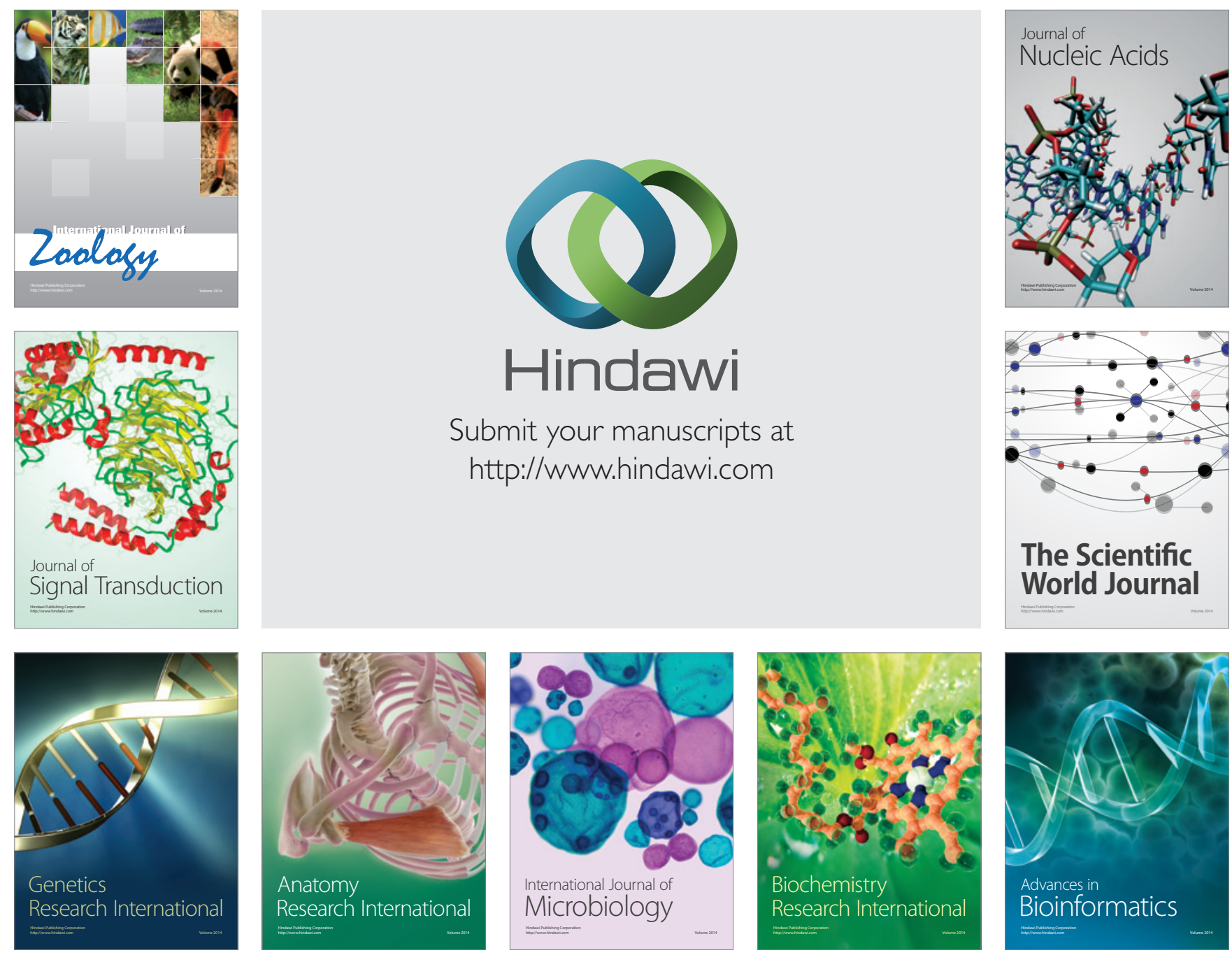

The Scientific World Journal
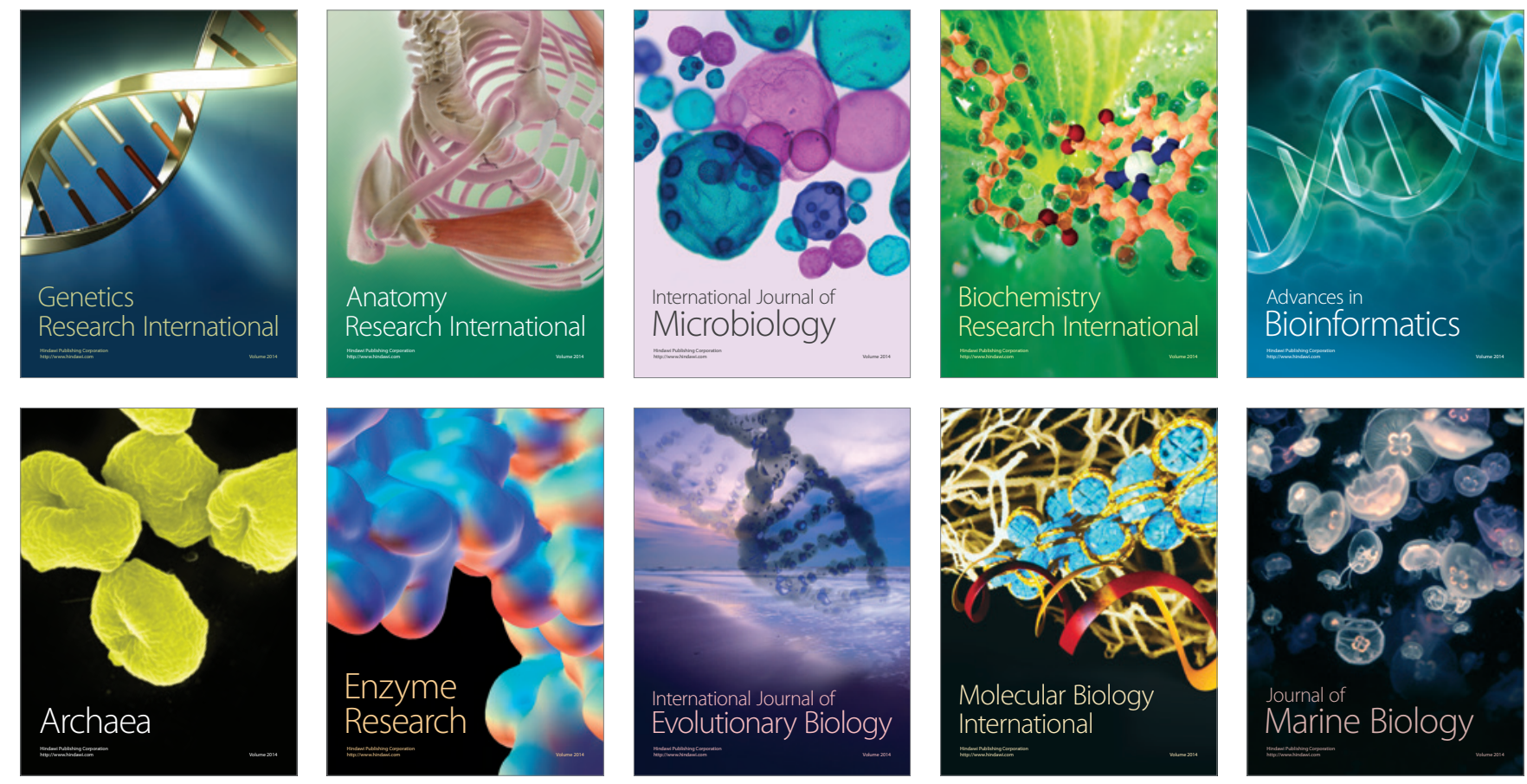